\title{
Transient state-dependent fluctuations in anxiety measured using STAI, POMS, PANAS or VAS: a comparative review
}

\author{
Running head: Self-Report Measures for State anxiety
}

Valentina Rossi \& Gilles Pourtois

Department of Experimental Clinical and Health Psychology, Ghent University, Belgium

\section{Corresponding author :}

Dr. Valentina Rossi

Department of Experimental Clinical and Health Psychology

Ghent University

Henri Dunantlaan 2

9000 Gent

Belgium

Tel: +329264 6472

Fax: +3292646489

Email: Valentina.Rossi@UGent.be

Prof. Dr. Gilles Pourtois

Department of Experimental Clinical and Health Psychology

Ghent University

Henri Dunantlaan 2

9000 Gent

Belgium

Tel: +3292649144

Fax: +3292646489

Email: Gilles.Pourtois@UGent.be 


\section{Abstract}

Several psychometric instruments can be used to measure state-dependent variations in anxiety, including the State-Trait Anxiety Inventory (STAI), the Profile Of Mood States (POMS), the Positive and Negative Affect Schedule (PANAS) and the Visual Analog Scales (VAS). Each of these instruments rests on specific theoretical assumptions about the construct of State Anxiety, and has been widely used for this purpose in different research domains. However, it remains difficult to determine what may be the specificities of these four instruments, when the goal is to measure transient statedependent variations in anxiety. In this work, we provide a systematic and comparative literature review of studies which have explored rapid fluctuations (i.e. test-retest intervals not exceeding 24 hours) in state anxiety by means of these specific instruments. Almost 200 studies were eventually included in our review. This comparative review confirms that, despite some disparities and specificities, each of these four instruments provides a reliable measure to capture rapid state-dependent variations in anxiety, although they have been used in non-overlapping research domains or experimental contexts.

Keywords: State anxiety, Self report, STAI, POMS, PANAS, VAS

Total number of words: 13,284 (references excluded) 


\section{State anxiety: construct and measures}

The compelling observation that specific unpleasant emotional conditions, characterized by short-lived feelings of tension or apprehension, are actually prone to fluctuations depending on external contingencies in the environment was first put forward by Cattell (1966; Cattell \& Scheirer, $1958 \& 1963$ ) in the second half of the last century, when he proposed the distinction between state anxiety and a more stable personality trait (referred to as trait anxiety), the latter being related to the tendency to experience feelings of tension and worrisome thoughts. Since this pioneering work, although no consensus has been reached about the true nature of state anxiety as a psychological or physiological construct, this concept has been further elaborated and refined by Spielberger (1966 \& 1976) at a theoretical level, and it has been implicated in a myriad of empirical studies that have helped delineate and better characterize the numerous psychological reactions to stressors in humans (e.g., Moser, Hajcak, \& Simons, 2005; Amir, Weber, Beard, Taylor, \& Bomyea, 2008; O'Brien, Terry, \& Jimmieson, 2008), or the physiological activations of the nervous system triggered by external or internal emotional stimuli (e.g., Swartzman, Edelberg, \& Kemman, 1990; Chua, Krams, Toni, Passingham, \& Dolan, 1999; Carrillo et al., 2001; Lucas et al., 2006; de Rooij, Schene, Phillips, \& Roseboom, 2010).

Levels of trait anxiety are considered crucial for people's successful adaptation to the environment, and have been shown to influence a multitude of core psychological components, including well-being and mental health (e.g., Duncko, Makatsori, Fickova, Selco, \& Jezova, 2006; Bruk-Lee, Khoury, Nixon, Goh, \& Spector, 2009). Consequently, good instruments for measuring stable inter-individual differences in anxiety proneness, considered as a personality trait, have been developed in the affective sciences literature (e.g., Cattel \& Scheirer, 1963; Spielberger, Gorsuch, \& Lushene, 1970), with the underlying idea that such trait is long lasting and mostly stable across time and situations. At the same time, a 
growing number of studies suggested that trait characteristics of anxiety not always accurately predicted psychological responses in specific situations (e.g., Andrykowski, Redd, \& Hatfield, 1985; Andrykowski \& Redd, 1987; Perry, Parker, White, \& Clifford, 1994), nor did they always show a straightforward relationship with the magnitude of anxiety fluctuations over time in response to external events (see Spielberger, 1983; Caumo et al., 2000). In these cases, a less stable measure of anxiety, able to capture these short-lived variations in the state of the individual would be desirable.

In order to appropriately meet these theoretical and empirical considerations, several instruments have been developed over the years, providing alternative instruments for measuring state-dependent fluctuations in anxiety, or more broadly, in affect or mood. Among these instruments, four self-report measures have been widely used in the affective sciences literature: the State-Trait Anxiety Inventory (STAI, Spielberger et al, 1970); the Profile Of Mood States (POMS, McNair, Lorr, \& Droppleman, 1971); the Positive and Negative affect Schedule (PANAS, Watson et al., 1988), and various Visual Analog Scales (VAS), among which the Visual Analog Mood Scales (VAMS, Stern, Arruda, Hooper, Wolfner, \& Morey, 1997) and the VAS-Anxiety (VAS-A). The aim of our review is to introduce and compare these four dominant measures as they have commonly been used in the literature across various domains and disciplines.

\subsection{Goals of the study}

As it will become evident from the specific sections concerning each of the aforementioned measures (see here below), they are all characterized by good psychometric properties. More specifically, they all provide rather sensitive estimates of fluctuations in anxiety. Capitalizing on their validity and flexibility of application, their use has rapidly led to the development of many research lines, resulting in an almost countless number of scientific publications available today. Accordingly, an attempt to provide a clear overview of their different fields 
of application has become increasingly difficult. Surprisingly, no explicit attempt has been done in this direction so far, and the unique resources summarizing the literature on selfreport measures of state anxiety remain the comprehensive bibliographies of the individual instruments (e.g., Spielberger, 1989, for the STAI, and McNair, Heuchert \& Shilony, 2003, for the POMS). Moreover, systematically comparing the psychometric properties of each measure seems rather difficult, since they have to be retrieved from various and sometimes scattered sources, such as the manuals and a set of psychometric papers addressing different combinations of instruments, with sometimes a lack of consistency across analysis techniques, sample types and research domains (e.g., Chlan, 2004; Stern et al., 1997; Millar et al., 1995). Ideally, psychometric assessments of the four instruments in the same samples, with systematic variations of the contexts, would need to be carried out in such a way to obtain comparative information at the psychometric level. Alternatively, a meta-analysis comparing the four instruments as used in the existing literature might help to gain insight into their specificity and sensitivity within certain domains. However, to the best of our knowledge, no such attempt has been made or is available in the literature so far. Many practical and/or theoretical reasons may potentially explain this lack of systematic comparison of these four instruments. First, as our systematic review suggests, the number of contributions is overwhelming and their contents heterogeneous, such that any attempt to summarize and integrate concurrently all these individual contributions into, for example, a meta-analysis, remains extremely challenging. Second, another major problem arises, as these instruments have primarily been used in different fields or domains, which renders any systematic or statistical comparison across these instruments almost impossible. Finally, it must be emphasized that it remains highly challenging to directly compare the psychometric properties of these instruments, which are in essence very different from each other (e.g. whereas the VAS-A is a single-item scale, the POMS is composed of 65 mood 
adjectives/items). Given these existing difficulties and limitations, the goal of our review is certainly not to carry out a systematic comparison of the psychometric properties of these four instruments. Before such a useful work can be initiated, a rough comparison of these four instruments, as well as their preferred domains of application, is first required. This is precisely the purpose of our systematic and descriptive review, whose potential value is thus to provide a first systematic attempt to acknowledge this inherent complexity, and propose a set of classification variables that may eventually help researchers and clinicians in their selection of an instrument (or combination of instruments) aimed at capturing state-dependent variations in anxiety.

In sum, the goal of our review is threefold: (i) first, we provide brief and consistent descriptions for each of the four instruments, including a careful presentation of their individual psychometric properties in relation to state anxiety. (ii) Second, we review the available psychometric data looking at convergent or discriminant validity as they have been reported in the reviewed studies, keeping in mind that all possible comparisons across the four instruments have not been performed yet in the literature, and hence the strength of the conclusions remains limited. (iii) Finally, our goal is also to provide a clear and transparent reading structure of the existing literature addressing questions related to the state anxiety construct, as explored using diverse methodologies and across different domains. Such an effort is worthwhile, as it enables to make more explicit some of the common associations made between specific measures and specific sub-domains within the affective science literature. Accordingly, our review work should provide initial clarifications of the possible reasons explaining some of these strong and common associations. Moreover, we also provide some general guidelines for the use and application of these four different instruments, when they are used to capture state-dependent variations in anxiety. As a result, our systematic review might turn out to be valuable for many researchers interested in 
capturing state-dependent fluctuations in anxiety, who are frequently confronted with difficulties when deciding which self-report measure might be the most relevant or appropriate to address a specific research question.

\subsection{Methods}

As we have already alluded to here above, the extant literature on state anxiety using the aforementioned four measures has become impressively vast and differentiated. Hence, in order to efficiently read transversally across this impressive amount of studies and find some unifying factors or variables, we adopted a standardized and quite restrictive "data-driven" approach to perform our literature review. As a first introductory step, we thoroughly present the exact criteria taken up for selecting these specific self-report measures (and not other ones), along with the criteria adopted for either including or excluding single studies from the large pool of available scientific resources. Furthermore, we list and precisely define the descriptive classification criteria used for the hits retained in our review.

\subsubsection{General inclusion criteria for the existing self-rating instruments}

As it turns out, a large number of self-report measures are nowadays available in the literature to measure anxiety, both in clinical or healthy populations. However, only a subset of selfrated instruments is actually relevant for assessing state-dependent changes in anxious responses, while the majority of the tools are mainly designed and used for measuring the more stable dimension of trait anxiety (for an overview of existing trait anxiety measures, see Elwood \& Olatunji, in press). Among the instruments that allow repeated assessments of anxiety with short time frame instructions, the tools that were primarily included in our review were the ones most widely used in the literature, best characterized by very good to excellent psychometric properties, and usually applied for scientific research purposes, both in clinical and non-clinical samples. These tools include the State-Trait Anxiety Inventory (STAI), the Profile Of Mood States (POMS), the Positive and Negative Affect Schedule 
(PANAS) and the Visual Analog Scales (VAS). Other self-report instruments often used in the literature to capture state-dependent changes in anxiety are the Hamilton Anxiety and Depression Scale-Anxiety (HAM-A; Hamilton, 1959), and the Hospital Anxiety and Depression Scale-A (HADS-A; Zigmond \& Snaith, 1983). However, these two latter scales were excluded from our systematic review because they have been used almost exclusively in clinical settings. Other measures, such as diaries, although extremely useful in clinical and non clinical settings, have been considered not relevant for this review either, mainly because they are not commonly used for repeated assessments using short test-retest intervals. Moreover, additional instruments, such as the Subjective Units of Distress Scale (SUDS; Wolpe, 1958 \& 1990), the Tension and Effort Stress Inventory (TESI; Svebak, Ursin, Endresen, Hjelmen, \& Apter, 1991) or the Emotion Assessment Scale (EAS; Carlson et al., 1989), have been considered as well, but given their limited dissemination, they were not included in our review ${ }^{1}$. The same restriction has been applied to the different questionnaires designed to assess very specific subtypes of anxiety (as opposed to state anxiety defined as a general/uniform construct), as the Smith Somatic Stress Symptoms Scale-State (SSSSS-S; Smith, 1990), the Competitive State Anxiety Inventory (CSAI-2; Martens, Vealey, \& Burton, 1990), the Job Anxiety Scale (JAS; Linden, Muschalla, \& Olbrich, 2008), the Dental Anxiety Scale (DAS, Corah, 1969) or similar more specific instruments.

\subsubsection{Description of the search strategy and specific selection criteria entailed}

To perform our systematic literature review we used multiple and commonly available search engines, including PsychInfo (from 1970), PsychArticles (from 1970), and the databases of ISI Web of Knowledge (namely, Web of Science ${ }^{\circledR}$, Inspec ${ }^{\circledR}$ and Medline ${ }^{\circledR}$ from 1975). More

\footnotetext{
${ }^{1}$ When compared to the four dominant self-report measures (STAI: 315 total hits; PANAS: 188; POMS: 196; VAS: 190), it becomes evident that the use of the SUDS (23 hits in Isi Web of Knowledge, 0 hits in PsychInfo and PsychArticles), EAS (0 hits in Isi Web of Knowledge, 5 hits in PsychInfo and PsychArticles) and the TESI (1 hit in Isi Web of Knowledge, 6 hits in PsychInfo and PsychArticles) remains limited.
} 
precisely, we searched these databases (upper time limit was April 2010) for hits containing "state anxiety", when combined with the following expressions or keywords: "STAI-S", "STAI-State", "STAI Y-1", "POMS", "PANAS", "VAS", Subsequently, we further refined our search in Web of Knowledge to studies falling under the domains "Psychology" and "Neurosciences". During a second stage, once the corresponding relevant contributions were all collected (i.e., 889 hits when collapsing across questionnaires and search engines), another restriction on the basis of the time frame used for the assessments was applied: we included in this review studies using the aforementioned self-report measures in the context of shortterm instructions (e.g., at the moment, in the past few minutes etc.), as opposed to trait-like instructions (e.g., in the past few weeks, or in general) since we aimed to study transient statedependent fluctuations in anxiety. Among them, we considered relevant for this review only studies carried out with repeated measures designs, in which two (or more) testing occasions were separated by short ${ }^{3}$ test-retest intervals. This systematic and narrow search of the literature resulted in a total pool of 197 studies using at least one (or sometimes a combination of) the self-report measures described here above (STAI, POMS, PANAS and VAS) and meeting all the aforementioned selection criteria. Among these 197 studies, 130 used the STAI, 70 the VAS, 40 the POMS and 33 the PANAS, either in isolation or in combination with another measure. Eighty-three studies used multiple measures. Clearly, the strength of this search procedure is that this specific outcome can be easily replicated by an independent researcher, if a similar literature search is performed with the same selection criteria, and using the same standard databases. The full bibliographical details of the

\footnotetext{
${ }^{2}$ Note that for the STAI-S the use of multiple research keys was required to overcome many inconsistencies in the way this specific part of the inventory has been commonly referred to in the literature, while for the three other questionnaires, a more widely accepted consensus regarding the use of the acronyms was found. In general, we adhered to the standard acronym used by the developers of the scales and reported in the published manuals.

3 'Short' has been formally operationalized as within the 24 hours. Although more longitudinal studies are certainly equally valid from a scientific viewpoint, we wished to focus in this review on "rapid" changes in anxiety and assess the ability of these four instruments to capture these fast and short-lived fluctuations.
} 
references/hits $(n=197)$ retrieved using the aforementioned search keys and criteria is provided as supplementary material, and thoroughly summarized in Table 1.

\subsubsection{Classification variables}

As a final step, we examined all the retained studies, and, in order to organize them in meaningful categories, we and carried out a systematic descriptive classification according to a limited number of variables. Six main classification variables were used: "construct", "domain", "population", “manipulation”, "direction of the effect”, and "approach". Note that these variables have been selected after careful consideration of the extreme variability across the retained studies, because, in the authors' opinion, they are good descriptors for the results, enabling comparisons among them despite their large heterogeneity. We have to acknowledge that other classification variables may be possible or acceptable, and were indeed initially considered by the authors (e.g., number of assessments; syndrome subtype in clinical studies; presence of concurrent non self-report measures, and so forth). However, these alternative variables have subsequently been excluded because they did not allow the extraction of any extra relevant information that could be used to better organize the different contributions included in our review. Moreover, we must add that each variable does not necessarily match a clearly identified concept of a putative theoretical model. Instead, the classification variables entailed are mainly descriptive and are based on the need of structuring the result of the search in an objective way, though respecting as much as possible the standpoint and interpretation of the authors of the original contributions.

Here below, we provide a list of the variables used in our review, with their corresponding labels and characteristics.

Construct: "Anxiety", "Affect", "Mood", "Stress", "Distress" or "Fear". This classification variable corresponds to the theoretical or empirical concept that the authors 
referred to, when articulating the research question or expected results. In this respect, most of the papers classified with the label "Anxiety" refer to a negative emotional state, characterized by a reaction of the organism (usually including changes in the body and the brain) to stressors, undermining the general well-being. Most of the studies did not provide any specific definition for anxiety when they referred to this construct; usually they simply reported the Spielberger's one (Spielberger, 1983). However, in a minority of cases, the authors were more specific in their definition, and they usually referred to anxiety as a physiological reaction to stress, mediated by subcortical circuits in the brain, involving emotional, behavioral, somatic and cognitive components (e.g., entry 145 in Table 1); this physiological reaction, in specific occasions (e.g., patients tested before undergoing surgery) might lead to increased responses to stressors. Obviously, this definition still remains relatively broad, and encompasses different aspects of anxiety. Nonetheless, in order to compare the 197 entries retained in our review, as well as to stick as much as possible to the specificities of the authors' concepts, which not always readily reflected the constructs which the single self-report measures were designed to measure, we had to include, besides "Anxiety", other labels reflecting state-dependent fluctuation in emotional response (i.e., "Mood", "Affect", "Stress", "Distress" and "Fear).

Domain: "Treatment", "Experimental", or "Applied". Under the label Treatment we categorized each manipulation that was designed by the authors in order to lower or downregulate anxiety levels. Examples of "Treatment" manipulations are pharmacological trials with anxiolytic drugs, alternative therapies as massage or aromatherapy, cognitive techniques (such as attentional bias or interpretation trainings), or more physical-oriented approaches (such as controlled bouts of aerobic gymnastics). By comparison, "Experimental" indicates that the manipulation was designed with the aim of inducing increases in anxiety levels either experimentally (with cognitive tasks, for example) or pharmacologically (with psychoactive 
or stress-resilience depressor drugs) ${ }^{4}$. We sometimes encountered studies in which, although the test-retest design criterion was fulfilled, no specific manipulation was visibly implemented. Representative examples are studies tracking affect fluctuations of circadian rhythm in healthy volunteers, or studies modeling the temporal dynamics of anxiety fluctuations in athletes during competitions. They have been included as "Applied".

Population: "Clinical" vs. "Non Clinical". With the Clinical label, we included studies that involved patients belonging to different "medical" groups, including cancer patients, anxiety spectrum disorder patients (Generalized Anxiety Disorder, Social Anxiety Disorder, Post Traumatic Stress Disorder, different phobias), depressed patients, psychiatric in- and outpatients, patients scheduled for elective surgery, or, more generally, any hospitalized patient under treatment or observation. Under the "Non Clinical" classification, were grouped the studies involving healthy participants, including in the subclinical domain (e.g., Table 1, entries 137, $154 \& 156)$.

Manipulation: "Central", "Peripheral” or "No Manipulation". This fourth variable refers to the content or modalities of the actual experimental manipulation performed by the authors in their study. A manipulation was considered "Peripheral" when it primarily targeted the body (or specific segments of the body), and used physical actions to directly intervene on it. Examples of studies meeting this criterion are all the ones involving treatments as massage or physical activities, but also the experimental ones involving manipulations of physical activity characteristics (for example, when acute bouts of gymnastics were manipulated in

\footnotetext{
${ }^{4}$ In specific cases, when an experimental design combined anxiety down-regulation (e.g., via drugs) with experimentally increased anxiety (by means of stress-inducing tasks, for example), the preferred label was "Treatment", because the experimental induction of tension or stress was meant to be only functional to the testing of the regulatory factor. On the other hand, when the positive outcome of an experimental manipulation was not expected or hypothesized a priori, or when both the directions of the effect were tested (for example, when exploring the effect of positive and negative interpretive bias training onto subsequent neutral tasks), the "Experimental" label has been chosen consistently.
} 
duration or intensity to model their effects on mood or affect, instead of being applied with the explicit aim to obtain a moderating effect on anxiety). With "Central", we included the studies capitalizing on cognitive processes for either up- or down-regulating state dependent levels of anxiety (such as the implementation of stressful tasks, exposure to threat stimuli, classical conditioning paradigms, attentional bias training and so forth). Noteworthy, common to all these tasks, is that the effect of the manipulation is assumed to be mediated by cognitive/central processes. As it turned out, we encountered special difficulties to ascribe one of these two labels to a group of studies where certain experimental manipulations were applied through one of the sensory modalities of the participants (e.g., music, bright light exposure, olfactory stimulations) or blindly taken in by the volunteers (as any medication in placebo controlled pharmacological trials), hence suggesting a bottom-up/peripheral action or way of delivery. In other words, in all these cases the participant was mainly a passive receiver of the experimental action, with no mediation of any conscious cognitive processes. Nonetheless, and crucially, all these experimental trials assumed that the treatment, or more generally, the manipulation used, actually targeted structures of the central nervous system. For this reason, we decided to ascribe to all the studies involving these types of manipulations the "Central" classification label. Furthermore, in another group of studies (mainly the ones classified as "Applied" following the variable "Domain", see here above) the authors did not use any manipulation in order to test their hypotheses, and accordingly, the label "No Manipulation" was ascribed to them.

Direction of the effect: "Induction" vs. "Regulation". This variable seeks to identify the direction of the effect evoked by the manipulation onto the levels of state anxiety, here coded on the basis of the expected results. Hence, a study aiming at showing a reduction of state anxiety after completing a given physical treatment (e.g., a sauna session), would be classified as "Regulation". When considering an opposite case, for example a study 
purposefully designed to measure the effects of increasing levels of state anxiety on decision making, this study would be classified as "Induction". Note that a combined label "Induction/Regulation" is possible for studies exploring the modulatory effects of treatments onto experimentally induced states of heightened anxiety.

Approach: "Descriptive" vs. "Causal”. This sixth variable refers to a binary classification. A study is considered "Causal" if the manipulation used in the experiment was purposefully designed to change levels of state anxiety. In all the other cases, namely when the manipulations were implemented for other purposes, and the fluctuations in state anxiety were measured only as a side effect, the study was classified as "Descriptive". For example, a study testing the relationship between Acute Tryptophan Depletion (ATD) procedures and amygdala reactivity to emotional stimulation, when the self-rated anxiety measures were eventually used only to control for undesired side-effects of the amino acid drink onto levels of affect (see entry 40 in Table 1), receives this qualification.

\section{Self-report measures capturing state-dependent fluctuations in anxiety}

\subsection{State-Trait Anxiety Inventory (STAI)}

\subsubsection{General description, main use and psychometric properties}

The State-Trait Anxiety Inventory (STAI) is a widely used instrument, primarily designed to measure anxiety either when it corresponds to a relatively stable personality disposition, or when it refers to a transitory emotional state, prompted by external or internal stimuli (Spielberger et al., 1970; Spielberger, 1983). Given the scope and aims of this review, here we mainly focus on the latest revised edition of the $\mathrm{STAI}^{5}$ (Form Y) and, more specifically,

\footnotetext{
${ }^{5}$ Since scores on STAI Form Y (Spielberger, 1983; Vagg, Spielberger \& O’Hearn, 1980) and STAI Form X (Spielberger et al., 1970) are highly correlated ( $r$ correlation coefficients ranging from .96 to .97 in American students), the use of the unrevised form may, in some cases, be accepted. Nevertheless, the use of the Y version is highly recommended because of its more stable and replicable underlying factor structure, obtained after having identified and replaced some items providing only poor psychometric properties (Spielberger, 1983).
} 
on its state part (STAI Form Y-1). Although a large number of names or abbreviations have been ascribed to this inventory, we will consistently refer to the State-Anxiety scale of the STAI (Form Y) as to the STAI-S. The STAI-S is a 20-item self-rating inventory composed of short verbal statements that participants have to rate using a 4 points Likert scale according to the subjective experienced intensity of each described feeling $(1=$ not at all, $4=$ very much so). The standard instructions stress the importance to perform the ratings using the intensity of feelings at the moment of the assessment (right now, that is, at this moment) ${ }^{6}$.

The factor structure of the STAI-S is characterized by two main dimensions (Anxiety-Present and Anxiety-Absent), which are each loaded by ten of the 20 items belonging to the inventory. The total score, obtained after summing up the scores obtained for the 20 single items, ranges from 20 to 80 points, with higher scores indicating higher anxiety levels. The scores for the 10 items loading the Anxiety-Absent factor are reversed before the sum is computed. Normative data for various English-speaking populations (e.g., students, adults in different age groups, military recruits) are reported in the Manual for Form Y (Spielberger, 1983). Noteworthy, translated forms of the STAI are now available in more than 60 languages and dialects (Spielberger \& Reheiser, 2009), and norms for the some of the translated versions are available in the literature. Moreover, guidelines for further linguistic adaptations are provided in the STAI (Form Y) Test Manual (Spielberger, 1983).

Overall, the STAI-S provides excellent psychometric properties: the internal consistency measured using Cronbach's alpha coefficient, ranges from good to excellent across several populations (e.g., between .86 and .95 in Spielberger, 1983; .94 in Creamer, Foran, \& Bell, 1995). Noteworthy, alpha coefficients are typically higher for the STAI-S when state anxiety is assessed under conditions of psychological distress, due to the peculiar positively skewed

\footnotetext{
${ }^{6}$ Simple modifications of the instructions enable flexibility, and yield similar assessments based either on previous (and still recent) moments in time (e.g., during the last block of the task, or during the therapeutic session), or for a future or hypothetical situation (just before or during a very difficult exam, for example).
} 
distribution of the STAI-S scores in relaxed situations, as compared to a more normal distribution under conditions of psychological stress (Spielberger, 1983; Spielberger \& Reheiser, 2009). Further evidence for the good reliability of the STAI-S is provided by relatively high item-remainder correlations (median $r$ range from .55 to .63 in several independent normative populations). At the same time, however, the stability of the STAI-S, as measured by test-retest correlations, is low (in the Manual's samples $r=.34-.62$, depending on the population and on the test-retest interval). Nonetheless, it is worth mentioning that given the transitory nature of the anxiety state that the STAI-S seeks to capture, low test-retest coefficients are actually expected, and even desirable to some extent (Spielberger, 1983). All in all, the reliability of the STAI Form Y-1 is very good. The same conclusion holds for the validity of this inventory. Construct validity is supported by the sensitivity of the STAI-S scores to manipulations of psychological stress: S-Anxiety scores are systematically higher when the inventory is administered just before or after stressinducing contingencies, or with the instructions to imagine being in such cases, as compared to administration in relaxed conditions. Since the evidence for concurrent and discriminant validity provided in the Manual mainly refers to the Trait Form of the STAI X, it will not be reported here ${ }^{7}$ (for details, see Spielberger, 1983). More relevant for the purpose of this work is the notion that the STAI-S items cover a wide item-intensity specificity range (i.e., the items differ in their sensitivity to diverse degrees and types of stress): because certain statements provide better discriminations at low anxiety levels, while others are more sensitive to variations in higher levels of stress, the STAI-S can be used to measure state anxiety under broadly varying stress conditions. For this reason, the use of the entire scale for

\footnotetext{
${ }^{7}$ Since the STAI-S was developed chronologically before other instruments measuring state anxiety, this may explain why no concurrent validity scores are provided in the Manual. In turn, the STAI-S has been used as reference for the validation of other instruments: for this reason, the correlation coefficients with the POMS, PANAS and VAS are reported in the sections concerning their respective psychometric properties (paragraphs 2.2.1, 2.3.1 and 2.4.1).
} 
measurement of state anxiety is highly recommended (Spielberger,1983). However, when shorter testing protocols are desirable (for either practical or clinical reasons), pruned versions are possible and acceptable. In this case, the single item-remainder correlations reported in the Manual should be taken into account when selecting the most optimal items while at the same time, the different item-intensity specificities should be evaluated in relation to the purpose and setting of the test (Bonke, Smorenburg, Vanderent, \& Spielberger, 1987).

\subsubsection{Practical usage}

The STAI-S is a brief and simple self-rating instrument, characterized by items covering a broad item-intensity specificity range. This feature qualifies it as a good measure for state changes in anxiety in a variety of experimental manipulations, both in clinical as well as subclinical populations. It must be noted that the Y form of the STAI was purified from items related to depression, mania or elation more than anxiety, and this version is therefore preferable to the $\mathrm{X}$ form (Spielberger, 1983).

An additional feature of this inventory is that it leaves out items reporting bodily correlates of anxious response (e.g. shaky, sweaty) in favor of more psychologically-based statements. As a result, this methodological choice leads to a less spurious measure of psychological states, as compared to other self-report measures (e.g., PANAS-X, which includes items as Shaky and Sleepy, see here below for detailed presentation).

As a last remark, since the STAI-S is primarily aimed at capturing subtle state fluctuations in anxiety driven by internal or external stimuli, it is recommended to administer it always before the Trait scale (STAI-T) in order to avoid unwanted priming effects of certain emotional states (e.g., tension).

\subsubsection{Main domains of utilization}


The STAI-S has been widely used for the assessment of state anxiety in response to various experimental manipulations in the context of psychological investigations. When reviewing the impressively large amount of studies using the STAI-S as outcome measure, it becomes rapidly obvious that the ease to administer this questionnaire, as well as the simple and straightforward scoring procedure, combined with the stability of the underlying psychological construct, have led many researchers to use this specific instrument. However, across these studies, a recurrent way of using this self-report measure is to administer it in combination with anxiety-inducing procedures, in order to assess the corresponding changes in levels of state anxiety. Diverse techniques or approaches have been developed for this purpose, among which cognitive and social stressors appear to be the most widely used. For example, a well validated procedure to successfully induce increases in state anxiety and mental stress is the Trier Social Stress Test (TSST, Kirschbaum, Pirke, \& Hellhammer, 1993, see Table 1 , entries 4, 5, 28, 33, 90, 92, 106, 109, $171 \&$ \& 193). In prototypical studies using this paradigm, participants are usually kept blind to the real purpose of the experiment (i.e., their actual response or resistance to the stressor), and are asked to complete the STAI-S, usually when entering the laboratory at the very beginning of the experiment. After obtaining this baseline measure of state anxiety, the experimental manipulation is usually applied, either to a subgroup of participants or to the whole sample. After the targeted manipulation has been performed, participants are typically informed of a stressful speech assignment, and state anxiety is assessed again using the STAI-S at the end of the preparation phase (that is, when anticipatory anxiety has presumably had the time to ramp up). Finally, the STAI-S is usually administered a last time after the end of the public speech task. Besides the TSST, several other manipulations have been successfully used to induce increased levels of mental stress, both in clinical and subclinical populations, when these changes were primarily measured using the STAI-S. These manipulations include stressful cognitive tasks involving 
mental calculations (entries 100, 123 \& 130), highly complex Tangram puzzles (entry 147), or high speed word processing tasks (entry 128), sometimes used in combination with exposure paradigms, in which fearful or phobic volunteers are briefly confronted to their threat-related objects (as in entry 154). Levels of anxiety have also been manipulated in healthy participants by means of exposure to various neutral stimuli which were designed to induce increases in tension (entries 30, 58 \& 136). Furthermore, in order to achieve modulations in state anxiety, mood induction procedures with pictures (entry 56), videos (entries $167 \& 184$ ) or virtual reality environments (entries 53, $67 \& 102$ ) have also been used in combination with the STAI-S as main outcome measure. The main reason or motivation to induce changes in state anxiety levels in these populations is either to study the psychophysiology of state anxiety (as in entries $123 \& 130$ ) or to measure the protective effects of treatments in interaction with ecological stressful situations (as in entries $100 \&$ 128). In this context, the high item-intensity specificity of the STAI makes it an extremely useful instrument, since it enables to capture subtle changes in anxiety, even when differences in baseline scores are reported, as in groups differing for their vulnerability to anxiety (see Bonke et al., 1987).

Whereas the majority of studies reviewed in our work and employing the STAI-S as an outcome measure used paradigms designed to induce anxiety in various ways (see Table 1, "direction of the effect" variable), a subgroup of studies have used the exact same instrument with the aim to explore possible reductions (or absences of change) of levels of state anxiety, in particular in clinical populations of patients undergoing surgery or anesthesia. Among these studies, the most common anxiolytic treatment that has been tested so far when the STAI-S is the main outcome measure, is exposure to music before medical operation (Table 1, entries 26, 36, 42 and 103). These studies demonstrated the high variability in the use of 
the STAI-S, usually with good results, even in clinical settings where the administration time must usually be kept as short as possible and the patient's burden limited.

\subsection{Profile of Mood States (POMS)}

\subsubsection{General description, main use and psychometric properties}

The Profile Of Mood States (POMS) consists of a list of 65 adjectives (e.g., Friendly, Tense) describing possible moods or feelings, each to be scored on a 5 points scale $(0=$ Not at all; 4 $=$ Extremely $)$ based on its compatibility with the participant's emotional state. Although judgments based on the feeling experienced in the past week (including the day of the test) are considered standard instructions of the POMS, more short-term requests (i.e., how are you feeling right now) can be used when investigating fluctuations of mood in relation to situational factors. Evidence was provided for independency of the POMS factor structure from the rating time frame (McNair et al., 1971, Appendix III). However, some caution is needed when comparing scores obtained using different temporal instructions to the general POMS norms provided in the Manual (McNair, Lorr, \& Droppleman, 1992). Various studies comparing right now and past week instructions reported inconsistent patterns of differences in all the factor scores for the two instruction sets, therefore it has been suggested that the sensitivity of the single items might be affected by the different temporal frames in certain samples (for details, see McNair \& Heuchert, 2005).

Six independent studies addressed the factor structure of the POMS during the development phase of the questionnaire construction (see McNair et al., 1971): they all yielded to a number of factors comprised between 5 and 7, with the most stable dimensions being Tension-Anxiety, Depression-Dejection, Anger-Hostility, Vigor-Activity and Fatigue-Inertia. An independent replication further confirmed the stability of the three subscales of AngerHostility, Vigor-Activity and Fatigue-Inertia, with less consensus for the Tension-Anxiety and Depression-Dejection dimensions, which were nonetheless detected in the two 
experimental samples (Norcross, Guadagnoli, \& Prochaska, 1984) ${ }^{8}$. The factors scores (obtained by adding up the single items scores within each sub-scale) can also be combined, with the Vigor score weighted negatively, in a Total Mood Disturbance Score (TMDS): the TMDS is presumed to be highly reliable because of high intercorrelations among the subscales (in particular in clinical populations), and it has even been proposed as a reliable measure of state anxiety because of its high correlation coefficients with the S-Anxiety scores of the STAI Y Form (Bolmont \& Abraini, 2001), at least under conditions of psychophysical stress. These results suggest that the TMDS may actually reflect a complex low mood pattern that could partially overlap with the construct of state-anxiety response, as captured by the STAI-S. Nonetheless, the psychometric properties of the POMS have always been reported separately for the five (or six) factors, and this approach will also be followed here. Furthermore, because of the specific purpose of this review work on fluctuations in levels of state anxiety, the attention will be primarily focused on the Tension-Anxiety dimension of the questionnaire.

Internal consistency of the Tension-Anxiety subscale is adequately high (Cronbach's alpha coefficients range between .90 and .92 in clinical populations, McNair \& Heuchert, 2005). As was the case for the STAI-S, the POMS test-retest reliability is also somehow low, even when used with the standard (past week) instructions. However, and crucially, the test-retest coefficients are higher when no treatment is applied between the test and retest measures $(r=$ .70 for Tension-Anxiety in psychiatric outpatients), and they decrease when external modifications (e.g., treatment) intervene before the retest phase $(r=.51)$. This sensitivity to change is even amplified when the short-term instructions (right now) are used, providing good evidence for the construct validity of the Anxiety-Tension state subscale (for details on studies using the right now instruction set in combination with emotion-inducing paradigms,

\footnotetext{
${ }^{8}$ A less stable factor of Confusion-Bewilderment and an additional unscored Friendliness dimension were isolated in a subset of populations, but were not always replicated.
} 
see Pillard, Atkinson, \& Fisher, 1967, and McNair \& Heuchert, 2005). Evidence for external validity has been provided by means of correlations with other measures capable of capturing contingent changes in state anxiety, including the STAI-S and the Positive and Negative Affect Schedule-Extended form (PANAS-X). The POMS Tension-Anxiety scores have been correlated with all the PANAS-X subscales (with past week instructions) and evidence was provided for convergent validity with the Fear subscale (correlation coefficient: .85) and for discriminant validity with all the other subscales of the PANAS-X (all $r<.74$ ).

Several short forms of the POMS have been developed for inclusion in multi-instrument assessment protocols or in order to be suitable for clinical settings in which the stress or pain experienced by the patients require less time-consuming testing procedures. The POMS-Short Form (POMS-SF, Schacham, 1983) consists in 37 items derived from the original version of the instrument, and it allows separate factors scores as well as a TMDS; its psychometric properties are considered good to excellent, and in certain cases (i.e., Tension-Anxiety subscale) even superior to that of the original POMS version containing 65 items (see Curran, Andrykowsky, \& Studts, 1995). The Brief POMS (Cella et al., 1987) is composed by only 11 adjectives, and it enables to compute only a global psychological distress index. Despite the good psychometric properties (Cronbach's alpha consistently reported above .90), the absence of more detailed information about possible dissociations among subcomponents of the total score is a major disadvantage of this shortened version of the scale. A 30 -items POMS (POMS-B) is available since 1989 (see McNair \& Heuchert, 2005): this version of the scale is composed by five items for each of the six subscales, and it has been developed pruning from the original self-rating scale, taking into account the loadings of each item on the separate factors. As a result, its psychometric properties are roughly similar to the 65items POMS (consistency for the Tension-Anxiety scale is .89 in a group of psychiatric male outpatients and .87 in the respective female group). As for the POMS-BF, the POMS-B 
maintains the level of specificity of the original version of the instrument due to the possibility of computing separate scores for the different subscales.

\subsubsection{Practical usage}

The POMS has been initially developed to measure affective states, and more specifically mood states. In this sense, the Tension-Anxiety factor of the scale identifies the tense mood as a possible counterpart of the concept of state anxiety, as directly measured for example by the STAI-S. Regarding the peculiarities of the POMS and its potential advantages over other self-rating scales, the presence of dissociated and very stable scales for Depression-Dejection and Anger-Hostility, besides the Tension-Anxiety scale, might turn out extremely helpful in further addressing the dimension-specific effects of treatments. As an example, given the large overlap of the anxiety and depression constructs (see Spielberger \& Reheiser, 2009; Cella \& Perry, 1986; Mineka, Watson, \& Clark, 1998, or Wolitzky-Taylor, Castriotta, Lenze, Stanley, \& Craske, 2010 for recent reviews on the comorbidity of the two disorders), a reduction along the depression dimension might go undetected when addressing possible mood changes using the STAI-S only. Consistent with this idea, evidence has been provided for a substantial overlap of the STAI-S score with the Total Mood Disturbance Score, which is a compound index and comprises all the POMS subscales (Bolmont \& Abraini, 2001). This enhanced sensitivity of the POMS towards differences among scales is supported by the broad range of adjectives included. At the practical level, however, the high specificity of the adjective list might be problematic when the scale is administered to patients with impaired language or verbal skills, or to people with limited lexicon; in such cases, it might be preferable to use non-verbal tools, such as the Visual Analog Scale (see here below). However, this drawback may be overcome, since the manual of this instrument also provides two possible alternatives for each of the 65 adjectives, in case the respondent would ask some clarifications concerning the exact meaning of some of the items. 


\subsubsection{Main domains of utilization}

The POMS has been used primarily as a measure of mood. However, our systematic review shows that a number of studies have used the POMS more specifically, to address the role of physical activity or bodily treatments (e.g., Johrei healing method, aromatherapy or massage) specifically onto levels of state anxiety. Typically, the POMS or a combination of different anxiety measures (usually POMS and STAI-S, see Table 1) is administered before the beginning of the treatment, and repeated again after it, seeking evidence for a decrease in state anxiety (see Table 1, entries 45, 54, 57, 62, 69, 70, 71, 84, $100 \&$ \& 107). Likewise, several studies have also used the POMS to investigate, using controlled designs, the anxiolytic effects of different physical activities, including single bouts of dynamic Taekwondo exercise (entry 183), Qigong exercise (entry 89), treadmill running (entry 132) and cycling (entry 174). Noteworthy, our review suggests that the POMS is rather seldom employed in clinical settings (cf. Table 1, entries 16, 41, 62, 78, 91, 125, 140 \& 182), and never, to our knowledge, with patients suffering from acute pain, due its somewhat lengthy duration of administration. The POMS is nonetheless used in pharmacological trials (entries 44, 64, 72, 121, 159, $160 \& 185)$. Additionally, in combination with the STAI-S and/or with Visual Analog Scales, the POMS is sometimes used to test for the effects of procedures of Acute Triptophan Depletion on mood (entries 41, 78 \&125 in Table 1).

To sum up, the results of this systematic review show that more than half of the studies meeting our general search criteria for this measure concern the positive influences of physical exercise or physical treatments, in the domains of sports and health psychology. Nonetheless, our review also suggests that the POMS is rather often used in psychopharmacology and, third, in the domain of experimental and applied psychology (roughly $20 \%$ of the studies reported in our review and using the POMS, see Table 1).

\subsection{Positive and Negative Affect Schedule (PANAS)}




\subsubsection{General description, main use and psychometric properties}

The Positive and Negative Affect Schedule (PANAS) was initially developed to provide a reliable estimate of two broad and largely independent factors implicated in emotional experience: Positive and Negative Affect (PA and NA). The original and most widely used version of the PANAS (Watson et al., 1988) is composed of 20 self-rating items corresponding to adjectives (e.g., Interested, Distressed) that describe different states, feelings and emotions. Each of the 10 terms linked respectively to NA and PA requires a score on a 5 points Likert scale. Each rating seeks to measure the intensity of that specific feeling or emotion during a given timeframe for the participant $(1=$ very slightly or not at all; 5 = extremely). As was the case for the POMS, simple amendments to the original instructions of the PANAS can be implemented to better address state fluctuations in PA and NA (using instructions asking to rate the feelings 'right now, at the present moment'), or instead, as a more stable measure of trait-like emotional disposition (in this case, the instructions are changed and state 'you generally feel this way, that is, how you feel on the average $)^{9}$. Here we will primarily focus on the specific properties of the instrument when used to capture transient state variations (and more specifically when these changes in affect primarily concern the NA factor). Accordingly, the psychometric properties will be reported with respect to the instructions requiring ratings of present affect.

The factorial structure of the 20 items version of the PANAS comprises only two orthogonal factors, each related to one of two primary dimensions of mood: Positive Affect and Negative Affect. The two scales exhibit acceptably high internal consistency (Cronbach's coefficient $\alpha$ for NA/present: .85), invariably low intercorrelations (-.15 for present instructions) and better test-retest reliability when the timeframe used in the instructions increases (test-retest correlation coefficients: NA/present: .45; NA/general: .71). The NA scale is composed by

\footnotetext{
${ }^{9}$ Between these two extremes, a wide variety of time frames can be tested, depending on the modifications made to the original task instructions (for details on this topic, see the technical Manual; Watson et al., 1988).
} 
items with high loadings on one factor and acceptably low loadings on the other one, providing therefore quite pure markers of one out of two dimensions: for the 10 items in the NA scale, loadings on NA factor are comprised between .52 and .74 , while loadings on PA factor are all lower than $|.15|$ (symmetrically, similar values are reported for the items loading the PA dimension, see Watson et al., 1988). Additionally, the internal validity of the scale is high, both for convergent (NA/present: .91) and discriminant (-.15) correlations (obtained with factor analysis: for further details, see Watson et al., 1988). The external validity of the tool has been tested by means of correlation scores calculated with other instruments measuring distress (and psychopathology). For the purpose of this study, the only relevant comparison (i.e., correlations with a measure of state NA) is the one performed with the STAI-S (Form X, Spielberger et al, 1970), where correlations of .51 were found, indicating mildly good external concurrent validity.

An expanded form of the PANAS (PANAS-X, Watson \& Clark, 1994), whose psychometric properties closely resemble the original version (NA/present: Cronbach's $\alpha: .85$; internal convergent validity.89 to .94 ; internal discriminant correlations: -.05 to -.16 ; scales intercorrelation: -.06) is also available ${ }^{10}$. Unlike the original version of the instrument, which is based on a conceptualization of the affective structure as a two-dimensional construct (composed by NA and PA, represented as distinctive and orthogonal factors), the PANAS-X is based on a hierarchical structure, which comprises two broad, higher order dimensions (again, NA and PA), each composed by several lower-order sub-scales corresponding to separate affective states. In this expanded scale the higher order constructs indicate the valence of the emotional state, while the correlated, and nonetheless distinguishable, lower order dimensions are specifically related to the content of the experienced affect. The eleven

\footnotetext{
${ }^{10}$ The internal validity coefficients provided for the PANAS-X were obtained with correlations between the NA and PA scales (PA scores non reported here) and regression-based scores on the first two Varimax Factors in the samples assessed with the original 60 PANAS-X Mood Descriptors.
} 
sub-scales of the PANAS-X (Fear, Sadness, Guilt, Hostility, Joviality, Self-Assurance, Attentiveness, Shyness, Fatigue, Serenity and Surprise), composed by uneven numbers of items (for a total of 60 adjectives), can be further grouped into three intermediate subcategories on the basis of their intercorrelations and loading values on the two higher order dimensions (NA or PA). The Basic Negative Emotion Scales comprise items with highest loadings on Fear, Sadness, Guilt and Hostility, which are in turn intercorrelated and have high loadings on NA (convergent correlations between .69 and .79, discriminant correlations $<|.27|$ for $\mathrm{NA} /$ present). Particularly relevant in the context of this review work is the Fear subscale, which has some clear resemblance with the STAI-S, and with the AnxietyTension scale of the POMS. The internal consistency of the PANAS-X Fear subscale (tested with present instructions) is acceptably high (Cronbach's $\alpha: .87$ in American undergraduate students, Watson \& Clark, 1994), and its external validity, as expressed in correlations with the different subscales of the POMS ${ }^{11}$, is adequately high (convergent correlation with the anxiety-tension POMS dimension: .85; discriminant correlations with the other dimensions of the POMS: all $r<.74)$. Although the psychometric properties of the hierarchical form of the PANAS (PANAS-X) have been reported to be acceptably good and stable across different samples (Watson \& Clark, 1991 \& 1992), the factorial structure of the NA sub-scales has been questioned (Bagozzi, 1993).

\subsubsection{Practical usage}

The PANAS Negative Affect scale does not provide a direct and explicit measure of state anxiety per se. Nonetheless, both the NA scale and, even more specifically, the Fear subscale of the PANAS-X contain items that are closely related to the definition of anxiety as a

\footnotetext{
${ }^{11}$ Note that in contrast with the other psychometric properties reported here, which were calculated with present instructions, the external validity coefficients of the PANAS-X have been calculated with past few weeks instructions. For further details on the PANAS-X psychometric properties with different timeframe instructions, see Watson \& Clark, (1991, 1992 \& 1994).
} 
'general or long lasting state of distress, prompted by not explicit or generalized cues' (cf. Lang, Davis, \& Öhmans, 2000). Accordingly, these subscales have consistently been used to address phasic changes in anxiety (or in certain specific cases, stress). In line with this notion, the PANAS and PANAS-X external validity measures provided by the authors (Watson et al., 1988; Watson \& Clark, 1994) give acceptably high convergent correlations with the POMS Anxiety-Tension subscale and with the State-Trait Anxiety Inventory-State Form ( $r=$ .85 with the POMS Anxiety-Tension subscale and .51 with the STAI-S, both with Past few weeks instructions, see Watson \& Clark, 1994 \& Watson et al., 1988, respectively). The critical items, which are strongly and consistently loading the Basic Negative Emotion Scales in the PANAS-X or the NA scale in the 20-item version of the instrument are Afraid, Scared, Frightened, Nervous, Jittery, Shaky, Upset and Distressed. In contrast to the STAI-S, which includes items assessing the Anxiety-Present and Anxiety-Absent constructs independently, the PANAS and PANAS-X scales do not comprise items related to the absence of anxiety. Nonetheless, the PANAS-X Self Assurance scale (comprising items as Fearless and Confident) and the Serenity subscale, belonging to the Other Affective States group and represented by items as Calm or Relaxed, could be used as measures of the Anxiety-Absent construct.

\subsubsection{Main domains of utilization}

The PANAS and the PANAS-X scales have been widely used to investigate changes in positive or negative affect states in healthy volunteers, mainly in experimental contexts aimed at either up- or down-regulating stress responses. The PANAS as outcome measure for anxiety has often been used in combination with anxiety-inducing procedures (see Table 1, entries $2,19,30,40,52,66,76,115,117,136,142,146,156,168,171, \& 192)$, among which the TSST (see also section 2.1.3). As was the case for the application of the TSST in combination with the STAI-S, studies using the PANAS as a measure of anxious reactions 
have applied experimental designs requiring multiple measurements of positive and negative affect, which were assessed at baseline (i.e., before the primary manipulation), a second time before the TSST, and a third time at the end of the speech, in such a way to be able to eventually model the time course of anxious reactions to multiple stressors (see entries 117 , 142 and 171 in Table 1). However, our systematic review suggests that, whereas the TSST has often been used in combination with the STAI-S to verify changes of the emotional responses in relation to the stressor, the same TSST and other anxiety induction procedures (e.g. the presentation of unpleasant pictures or sentences) were used in the literature in combination with the PANAS in order to quantify the effects of the induced stress on other cognitive aspects, including decision making processes or patterns of regional brain EEG activity (Table 1, entries $171 \&$ 146). Furthermore, the PANAS has sometimes been used to assess the compensatory effects of cognitive restructuring protocols (entry 156) or positive imagery (entry 75) onto induced stress responses.

Besides this main domain of application, the PANAS has also been used frequently in different fields (e.g., sports and health psychology), in order to assess the positive effects of physical exercise on mood and affect (and more specifically onto negative affect and anxious feelings). In this context, the PANAS has been administered before and after exercises varying in type (Table 1, entry 43), intensity (entries $9 \& 20$ ) or duration (entry 152). Interestingly, the PANAS has been also associated with the STAI-S to assess the positive effects of gymnastics on emotional state (entries $86 \& 87$ ), and to compare changes in levels of state anxiety caused by bouts of activity in various disciplines, including Yoga, walking, martial arts, cycling and aerobic gymnastics (entries $21,97 \& 129$ ).

In summary, our review shows that the PANAS and PANAS-X scales have mainly been used in experimental paradigms aimed at characterizing factors or conditions able to influence both positive and negative affect (and among the components of NA, state anxiety). By 
contrast, it turns out that this instrument has only rarely been used with clinical populations to capture transient state-dependent variations in mood or affect (see entries 21, 136 and 146 in Table 1).

\subsection{Visual Analog Scale-Anxiety (VAS-A)}

\subsubsection{General description, main use and psychometric properties}

The Visual Analog Scales, or Graphic Rating Scales, as they were originally coined, have been introduced in 1923 by Max Freyd, for the purpose of achieving an unbiased judgment of psychological or behavioral characteristics. A VAS is composed by a line whose limits are anchored by two terms representing the extremes of the addressed sensation, and by an introductory question (e.g., How anxious do you feel right now?). This form of self-rated measure can be used in combination with several adjectives or statements (e.g., tense, shaky, restless) in order to obtain a measure of these attributes, which is at the same time precise, accurate, sensitive to change, but also not very burdensome in completion for clinical populations. Additionally, due to its intrinsic simplicity, the VAS is a suitable instrument for repeated measurements, also in clinically restraining situations (e.g., directly in the operatory room). The patient is usually requested to mark the point, along the line, that corresponds best to the perceived intensity of the feeling that is mentioned in the question. This procedure has proven to be also suitable for patients with motoric or linguistic problems, or in state of acute stress, where omissions in more burdensome inventories (such as STAI or POMS) are frequent in clinical practice. The most commonly used VAS for the measurement of state changes in anxiety is the so-called VAS-A, composed by one single item proposing the question "How anxious do you feel right now?" followed by a line delimited by two anchors "Not anxious at all" on one side and "As anxious as I could be" on the other side (or similar statements, for example "No Anxiety at all" and "Worst anxiety imaginable"). With some exceptions (see below the VAMS description) the null anxiety anchor is usually positioned at 
the far most left of the line, or at its bottom in case of a vertical format, while the extreme anxiety anchor is positioned at its right (or top). Scoring of the scale is calculated either with a ruler, measuring the distance in millimeters from the null anxiety anchor to the mark, or with stencils, which permit differentiation in the attribution of values to the positions on the basis of distributional properties (Freyd, 1923).

The psychometric properties of the VAS-A have been addressed both for the horizontal and the vertical version of the instrument in several clinical and subclinical populations (Hornblow \& Kidson, 1976; Vogelsang, 1988; Gift, 1989; Cline, Herman, Shaw, \& Morton, 1992; Millar, Jelicic, Bonke, \& Asbury, 1995; Kindler, Harms, Amsler, Ihnde-Scholl, \& Scheidegger, 2000; Chlan, 2004). They are quite acceptable, although internal consistency of the scale is not available, since it is composed by one item only. On the other hand, its validity has been addressed by several studies in clinical and nonclinical populations, leading to the conclusion that this instrument is suitable for assessing state changes in anxiety, knowing that the vertical version of the VAS-A seems to be more sensitive to change in affect than the horizontal one (Gift, 1989). The external validity has been reported in numerous populations by means of correlations with STAI-S scores and other measures of anxiety: the correlation scores range from moderately low values ${ }^{12}$ (.52 in Cella \& Perry, 1986; .50 in Chlan, 2004) to relatively high coefficients (.82 in Vogelsang, 1988). This wide variability somehow suggests that caution is needed when assuming the same psychometric properties for the VAS-A in different populations (see also Hornblow \& Kidson, 1976, reporting very different correlation coefficients between STAI-S and VAS-A across several populations). Concurrent validity has also been calculated in respect to the POMS-Tension ( $r$

\footnotetext{
12 Both the VAS-A and the STAI-S presumably provide an estimate of the same, very specific, construct (namely, anxiety), such that these two instruments should normally share a high portion of variance. Accordingly, correlation coefficients ranging between .34 (Hornblow \& Kidson, 1976) and .52 (Cella \& Perry, 1986) may be considered moderately low in this context.
} 
$=.51$, while discriminant correlation coefficients were provided in the same sample with measures of depression (all $r$ s $<.49$, Cella \& Perry, 1986)

Test-retest reliability data have been provided both in healthy populations (between .30 and .32 Hornblow \& Kidson, 1976; >.50, Cella \& Perry, 1986) and in the context of carbon dioxide breathing challenges in panic disorder patients (see entry 189 in Table 1). Prechallenge VAS-A scores, as well as post-challenge scores and difference/delta scores (obtained after subtracting the pre-challenge scores from the post-challenge, usually higher, ones) were reported for two identical sessions one week apart. Correlation coefficient between scores in the two sessions ranged from .058 for the pre-challenge score to .401 for the delta score and .709 for the post-challenge score, providing evidence for both sensitivity to variable situational factors (pre-challenge low correlations) and for stability in the sensitivity to change (high post-challenge coefficients). This study also pointed out that VAS delta scores might not be the best way to assess anxiety induction, because of their strong dependence to the (unstable) pre-challenge scores.

Several variations in the VAS-A construction and application have been proposed in the past years, leading to instruments with different strengths and weaknesses: the analog scales can be presented in discrete Likert-scale form with verbal instructions (Verbal Anxiety Rating, VAR; entry 18 in Table 1), which leads to smaller omission rates as compared with the visual analog version of the scale, but also to a loss of responsiveness linked to the limited amount of discrete descriptors, as compared to the continuous version (Davey, Barratt, Butow, \& Deeks, 2007). Alternatively, the VAS-A has been combined with other scales assessing emotional states, either in vertical Likert-scale format with the null anchor below (as in the Emotion Thermometers: Mitchell, Baker-Glenn, Granger, \& Symonds, 2010 \& Mitchell, Baker-Glenn, Park, Granger, \& Symonds, 2010) or in vertical VAS format, with the neutral anchor above (Visual Analog Mood Scales, VAMS: Stern et al., 1997; Nyenhuis, Stern, 
Yamamoto, Lucchetta, \& Arruda, 1997). The VAMS version of the VAS-A showed good convergent and discriminant validity, as expressed in the correlation coefficient of the separate VAMS with the different POMS subscales (convergent validity coefficients of the Afraid VAMS with the Tension-Anxiety scale of the POMS: .34 to .54 in different samples; mean discriminant validity with non-homologous scales: .16 to .35 ; mean inter-correlation among VAMS: .14 to .29); acceptable psychometric properties have also been reported for the Anxiety Emotion Thermometer (sensitivity measured using the cutoffs of the Hospital Anxiety and Depression Scale: .92; specificity: 0.61).

\subsubsection{Practical usage}

All in all, systematic research has shown that the VAS-A, in its different declinations, generally performs well in capturing dynamic changes in experienced anxiety state, and can easily be used in clinical contexts. Nonetheless, some recommendations should be made in constructing, standardizing and even simply using VAS scales. First, a very specific unipolar construct should be used in the introductory question and in the verbal anchors. Since many feelings and states can have multiple opposites, only one dimension should be tested in each VAS (Freyd, 1923). The VAS-A (Hornblow and Kidson, 1976), and several other adjectives have been used to assess various constructs. Since the scale is not bound to specific questions, the experimenter or clinician has the freedom to adjust the question and the anchors at his own convenience. However, certain scales have been tested and standardized or validated in the literature, and the recommendation is to adhere as much as possible to one (or more) of them. Some examples of the items used in previous studies addressing the changes in anxiety in diverse clinical populations are the adjectives afraid and tense (used in the VAMS), and statements regarding the amount of perceived fear (entry 73 of table 1), or the possible correlates of preoperative anxiety (Kindler et al., 2000). Since the scale has been developed in order to match the needs of clinical populations, the instructions and the 
introductory questions should be as simple as possible, in order to minimize omission rates, and contain examples of possible scores (Freyd, 1923; Davey et al., 2007). Moreover, unless a Likert discrete format is used, the VAS line should be continuous and not too long, since it should be perceived as a whole by the participant (Freyd, 1923). Nowadays, automatically scored electronic versions of the VAS-A are commonly available for clinical and non-clinical use, and evidence has been provided for their equivalence with the paper version (van Duinen, Rickelt, \& Griez, 2008).

Importantly, some caution is needed when assessing state anxiety levels using combinations of instruments including the VAS-A. This latter measure contains the word anxious; hence it is very overt or explicit to participants. Accordingly, it might be good practice to assess the VAS-A after the other measures, in order to prevent any biasing of the responses to the following measures due to the explicit mention of the word anxious. However, it must be noted that even questionnaires that are somehow more covert might prime anxious feelings, influencing the subsequent responses to the VAS-A. This problem is crucial in designs involving multiple instrument assessments, and, unfortunately, there is no 'gold standard' rule to deal with this problem in the literature (e.g., Millar et al., 1995).

Although the strengths of the VAS are the quick administration, the relative simplicity of the instructions and the smaller impact that language has on the comprehension and completion of the scale, some potential drawbacks of this way of assessing transient changes in state anxiety should be pointed out. First of all, as previously noted (Gift, 1989), some participants experience problems and uncertainty when translating a sensation into a spatial dimension, as required for the distance between a pre-defined anchor and an arbitrary mark on a straight line. These problems sometimes lead to clustering of the responses at the extremes and at the center of the scale, a phenomenon that might be partially attributed to the central tendency bias, a well known psychological phenomenon (Millar et al., 1995). Additionally, 
accumulating evidence obtained by the use of the VAS-A in different populations seems to suggest that the distribution of the scores is not always consistent, nor are the correlations with other state anxiety measures (as the STAI-S or the POMS Tension-Anxiety subscale). These observations suggest that norms and cutoffs for high anxiety categories should be obtained separately for different clinical population, and that additional research on the matter is highly desirable.

\subsubsection{Main domains of utilization}

The VAS-A is a tool that has explicitly been developed to be administered in clinical settings. Hence, it is not surprising to find out in our review that a majority of the relevant studies have used the VAS-A with patients. Consistent with this specificity, several authors have used the VAS-A to explore changes in state anxiety occurring directly within the operatory theater, mainly in patients undergoing surgery or painful dental treatments. The choice of measuring anxiety with a single VAS, or a cluster of them, allows multiple repetitions of the assessment, even during the peri-operative period, when the patients have already received partial sedation (Table 1 , entries $1,73,95 \& 110$ ). In these cases, an experimental manipulation is usually applied immediately preceding or instead of the pre-operatory medication, and the VAS-A is therefore used to test for the efficacy of the target manipulation to eventually reduce levels of state anxiety (e.g., entries $1,32,61,95,103,110,187 \& 195$ ). At the same time, our systematic literature review suggests that a second main domain of utilization of the VAS-A, concerns the psychopathology and neuropharmacology of disorders belonging to the anxiety spectrum, as Generalized Anxiety Disorder (GAD), Post-Traumatic Stress Disorder (PTSD), Phobias and Panic Disorder (See entries 4, 10, 12, 24, 41, 63, 78112 and 189 in Table 1). Moreover, several studies have explored the modulation of anxiety levels in other patient populations as a function of anxiety induction procedures (see entries 22, 85, 99 and 
153 in table 1) or dedicated pharmacological manipulations (e.g., entries 41, 78, 125, and entry 79 for a validation study on healthy participants.

\section{Comparative evaluation of the four instruments}

\subsection{Overlap vs. differences for the six classification variables}

When carefully looking at Table 1 and the way the six variables (section 1.2.3) account for the heterogeneity found across the 197 retained studies, we can identify some overlap, as well as interesting differences among the four instruments in the way they have been used in the literature to capture transient state-dependent fluctuations in anxiety. Most striking is their selective repeated association with different contexts or situations, as clearly reflected when considering the variables "Domain" and "Population" concurrently (see Fig. 1d). In this section, for each grouping variable separately, we first discuss the most evident similarities and differences between the four instruments, before we turn to some general conclusions and recommendations.

Construct: "Anxiety", "Affect", "Mood", "Stress", "Distress" or "Fear". This variable corresponds to the theoretical or empirical concept embraced by the authors in their original contribution: it always relates to the state anxiety domain, but sometimes inclusion of more specific or more general constructs was necessary. Based on our systematic review (see Table 1), it becomes obvious that the STAI-S and the VAS-A were the most widely used instruments when the underlying construct was clearly and transparently defined as "anxiety". Presumably, this relates to the unambiguous definition underlying the construct in case of the STAI, and the high specificity allowed by a single-item instrument for the VASA. Interestingly, our review shows that the most common multiple assignment is the combination of "anxiety" and "mood", whose measurements have been usually achieved by using the POMS in combination with the STAI-S. Interestingly, in several studies the concept of state anxiety closely resembles the concept of "negative mood" or "negative state", and in 
these specific case either the POMS alone (cf. Table 1, entries 14, 131, 135, $158 \& 174$ ) or the PANAS alone (entries 30, 40, $97 \&$ 156) was used. Conversely, the STAI, initially designed to selectively measure state anxiety, has been used sometimes to measure other constructs such as "negative affect" (see entry 25 in Table 1) "positive affect" (entry 114) "stress" (entries 123 and 175) or "mood" (see entries $87 \& 185$ ).

Domain: "Treatment”, "Experimental”, or "Applied”. At first sight, our review suggests an uneven distribution of the studies along these three categories for the four instruments. Whereas three of the four instruments (namely the STAI, the PANAS and the VAS) have primarily been used in studies focusing on experimental designs aimed at modeling changes of the phasic anxious responses, the POMS is distinctive as it has mainly been used in studies designed to treat anxiety states. This difference becomes even more obvious when plotting the four instruments onto a bi-dimensional axis taking into account two independent descriptive variables concurrently, namely "Domain" and "Population" (Fig. 1d). Figure 1d suggests non-overlapping mean positions for the different instruments along these two axes with a marked shift for the POMS towards the treatment direction, relative to the three other instruments.

Population: "Clinical" vs. "Non Clinical". For this variable as well, differences are visible across the four pre-selected instruments. As can be seen from Figures $1 \mathrm{~b} \& 1 \mathrm{~d}$, the PANAS has mostly been used in non-clinical samples while the VAS has been used equally in clinical and non-clinical samples to measure state-dependent variations in anxiety. The STAI-S and the POMS occupy relatively intermediate positions as compared to these two "extreme" cases (see Fig. 1b).

Manipulation: "Central", "Peripheral" or "No Manipulation". With respect to this grouping variable, again, dissociations are evidenced for the four instruments. As it turns out 
based on our review work, the POMS is distinctive as many studies that have used this instrument focused on manipulations targeting the body ("Peripheral"). By comparison, a majority of studies using the VAS (and to a lesser degree either the STAI-S or the PANAS) actually involved manipulations acting on the cognitive or central nervous system ("Central", see Figure 2a).

Direction of the effect: "Induction" vs. "Regulation". Figure $2 \mathrm{~b}$ shows the relative distribution of studies for this variable, separately for each self-report instrument. As can be readily seen, a strong difference is observed between the POMS and the VAS: while most of the studies using the POMS were primarily designed to assess down-regulatory affective processes, a majority of studies using VAS were set up to measure the reactivity of the organism in response to stress or anxiety induction. Interestingly, our review also shows that the highest proportion of studies including a combination of up- and down-regulatory processes actually had the STAI-S as outcome measure (Table 1).

Approach: "Descriptive" vs. "Causal". Our review suggests that this variable was the one providing the lowest discrimination power among the four instruments (see Fig. 1c). Although the number of studies included in our review varies substantially from one instrument to the other (ranging from $\mathrm{N}=130$ for the STAI-S to $\mathrm{N}=33$ for the PANAS), most of the studies were classified as "Causal" (i.e., the study was designed with the aim to influence levels of state anxiety), relative to "Descriptive" (i.e., the study was not set up for this goal), regardless of the instrument used (see Fig. 1c).

Based on this systematic evaluation of the four instruments using our six variables, a main conclusion that can be drawn is the observation of asymmetries or imbalances in the domains of utilization of these four instruments (STAI, POMS, PANAS and VAS). Based on our systematic review, it becomes apparent that these four instruments are used in different 
research domains, even if they are all applied to obtain a measure of state-dependent fluctuations in anxiety. When the testing takes place in a clinical environment, VASes clearly dominate, and are the most commonly used instruments, while by comparison, the use of the PANAS, for example, remains extremely limited (see Figures $1 \mathrm{~b} \& 1 \mathrm{~d}$ ). On the other hand, our review also indicates that when fluctuations in anxiety are measured and experimental designs are explicitly used, the STAI-S is the dominant instrument, and seems to be the 'gold standard' measure. In these cases, it must be emphasized that the construct under study is usually strictly and clearly characterized as "anxiety", as opposed to "affect", "mood", or "stress". Likewise, our review shows that when the research question involves measuring changes in anxiety (or mood) in response to specific treatment conditions administered to non-clinical samples, a majority of studies have used the POMS, which often appears to be considered the most valid instrument in these cases, because of its enhanced specificity in capturing and disentangling discrete effects of the manipulation on putative orthogonal factors (e.g., anxiety, depression or anger).

As anticipated in the introduction section, our review work did not aim, however, at establishing whether these differences found for the domains of utilizations of these four instruments actually result from their non-overlapping intrinsic characteristics (including at the psychometric level, as reviewed here above), rather than a simple tradition to use a specific instrument within a specific domain of investigation. To the best of our knowledge, this is still an empirical question, and no previous work has directly compared the sensitivity of all these four instruments in capturing fine-grained fluctuations in anxiety, when they occur within a short time period. Importantly, it must be noted that systematic comparisons between these instruments have been made (e.g., Davey et al., 2007; Chlan, 2004; Cella \& Perry, 1986), but these comparative efforts were mainly carried out to better characterize these instruments when considered only in a very specific domain at a time, as opposed to a 
systematic comparison of the sensitivity of these instruments across several or multiple domains. However, as a first attempt towards more systematic comparisons of these four instruments, we have extracted from the studies included in our review (when available), the reported psychometric properties, and summarized them in a Table (Table 2, supplementary material). From Table 2 it becomes obvious that certain properties of the measures match rather well with the ones provided in the manuals (see for example the internal consistency scores). However, it is also clear that other properties (such as test-retest reliability and intermeasure correlations) are not always reported. Moreover, when that is the case, interinstrument comparisons are often only partial, and moreover generalization across domains remains very difficult, due to the limited use of certain measures in certain domains. Nonetheless, with respect to basic psychometric properties, these four instruments are highly comparable and they provide reliable tools to measure state-dependent changes in anxiety. However, it is clear that more psychometric and comparative work is needed to precisely determine the respective sensitivity (and specificities) of each of these four instruments in relation to a specific domain of application.

\subsection{General recommendations for the use of the STAI, POMS, PANAS and VAS}

Our systematic review is also informative, as it enables to raise a few recommendations for the use of these four instruments in the context of rapid state-dependent fluctuations in anxiety. First of all, it seems particularly important to provide a clear, good and appropriate operationalization of the construct or variable under study, prior to the actual selection of a given instrument. Does the state-dependent changes under study concern anxiety per se, or instead negative mood, affect, stress or any other underlying construct? It seems relevant to clarify this issue from the outset, before using a specific instrument. If the core of the research question concerns "state anxiety", and the definition of anxiety most likely adheres to the one put forward by Spielberger (1983), the use of the STAI-S may be preferred, 
because of its wide item-intensity sensitivity, which makes it especially suitable tool to test state-dependent fluctuations in a variety of situations and samples (as shown in this review, see Table 1). If the study is performed with clinical patients and the protocol includes more restrictions or constrains (e.g. limited time to fill out a given questionnaire), the VAS-A stands as a the most optimal instrument to measure state-dependent variations in anxiety, keeping in mind the good correlation of the VAS-A with the STAI-S. Nonetheless, as directly pointed out by authors who compared the performance of the two instruments in clinical settings, some caution is needed when comparing results obtained using these two instruments, due to their different discriminant validity and sensitivity (Davey et al., 2007, and entries $18 \& 103$ in table 1; see also Table 2). Furthermore, our review also suggests that the PANAS or PANAS-X has explicitly been used in the literature not only as a measure of affect, but also of anxiety or negative mood (e.g., entries 25, 87, 97, 142 and 169 in Table 1). In particular, when the construct entailed is "fear" (rather than pure anxiety), the PANAS-X or a single VAS (e.g., entry 24 or 73 ) have been the preferred measures. Obviously, when more complex changes in affective state (as opposed to changes in the specific anxiety subcomponent), are targeted by the manipulation, the PANAS remains the most relevant instrument, although occasionally Positive Affect has been measured by using the STAI as well (e.g., entry 114 in table 1). Finally, the POMS remains the most suitable instrument in case not only the tension component of anxiety is under interest, but also the mood condition in a broader sense, and when specific effects onto diverse components of mood are hypothesized, also in light of the strong comorbidity between anxiety and depression. However, our systematic review also shows that, besides the POMS, other measures capturing changes in levels of state anxiety have been used when the construct under investigation was mood (e.g., entry 52, 86, 87, 97, 169 or 185), and might therefore be considered for future use. 
Obviously, our review work represents only a first, probably imperfect, attempt, aimed at classifying mostly at a descriptive level a large set of studies published across many different domains in the affective science literature, but which all share measurements of state anxiety using standard self-report measures. Based on the results of this first effort, it becomes clear that more research (including psychometric work) aimed at directly comparing these instruments (not so much with the aim to find similarities, but instead to better delineate the subtle differences and reciprocal strengths among them) would be desirable at this point. As such, our review may be a valuable first step for further research which will eventually help researchers selecting the most appropriate instrument (or combination of instruments) in light of their specific research question and domain.

\subsection{Added value of multiple measures?}

We have to acknowledge, based on our review work, that various combinations of these measures have been made in the literature, although it does not always appear clear why a combination, instead of a single instrument, was actually preferred. Among the studies using multiple assessment instruments for measuring state changes in anxiety, it must be noted that a few inconsistencies were noted, and as such, they may be informative. Hence, in a small number of studies (i.e., 11/83 where more than one instrument was used in the study), different results were obtained for the different instruments, suggesting some discrepancy. Although these inconsistencies remain overall limited (i.e., $13 \%$ of the studies in which multiple assessment tools were used), it is interesting to note that this ratio is comparable for the different combinations used: it ranges from $11 \%$ (when combining STAI-S and VAS-A) to $13 \%$ (when associating STAI-S and POMS). Notably, the authors often used multiple measures presumably in order to increase the number of variables tested at a specific time: for example, de-Paris et al. (2003) used a cluster of VASes to test anxiety, while the POMSBI was also used concurrently, but to assess state-dependent changes in mood. Nonetheless, 
in this study, results for the POMS Tension-Anxiety scale showed no effect of the manipulations (i.e. the implementation of the TSST while two different doses of Gabapentine were administered, relative to a placebo condition), although results for the VAS-Tension showed significant increases in response to the stressor. This type of dissociation between different instruments that are nonetheless assumed to tap into the same construct was also acknowledged by other authors, in the context of very diverse experimental designs, and with the use of different combinations of instruments (entries 21, 25, 72, 108, 110, 113, 140, 144, 149, 190). Obviously, in these cases where inconsistencies for the different instruments are reported, the question could be raised as whether a genuine effect of the manipulation in changing state anxiety levels could be assumed. Related to this fundamental question, is also the interrogation about how to deal with such inconsistencies when they appear, and whether the use of multiple measures (for example, using both STAI-S and VAS-A to assess changes in levels of anxiety provoked by a given manipulation) is truly desirable. It is difficult to make any recommendation about the use of a single, as opposed to multiple measures, as this question would need to be answered formally both at the empirical and theoretical levels, and to the best of our knowledge, no study has tackled this specific issue so far. As a caveat, we can add that if the two (or more) measure inform about the same construct ("state anxiety"), then using them in combination would not bring any additional information, as these measures would be merely redundant. Alternatively, if capitalizing on the differences between the instruments is the elective strategy to be eventually able to better describe the composite effects of a manipulation, then inconsistencies for these measures are actually informative and desirable, because in this latter case, they enable to rule out generic effects, and allow revealing more specific modulations. Thus, when using multiple measures and obtaining inconsistencies in the results for changes in state anxiety, this may be perceived as either as a positive outcome or not, depending on the way the added value for using multiple 
measures is articulated by the authors, as well as the way these inconsistencies are thoroughly discussed in the study. Therefore, we can only formulate here a prudent recommendation, which is to use a single measure to capture "rapid" state-dependent changes in anxiety, unless specific conditions are met, and the added value of multiple measures has been clarified.

\subsection{Conclusions}

The main goal of our review was to provide a clear and accessible reading structure for the numerous scientific reports that have explored across diverse domains "rapid" statedependent variations in anxiety using a limited set of self-report measures (STAI, POMS, PANAS or VAS). A total of 197 studies that fulfilled these specific criteria were eventually included in our review. The rationale was then to perform a systematic "data-driven" classification of this large pool of studies, using descriptive grouping variables providing the potential to better structure and delineate boundaries in this large set of heterogeneous studies. This work enables to show that these four different dominant instruments actually map onto different research domains, where the intrinsic specificities of each tool in capturing these state-dependent variations in anxiety seem to have been exploited and maximized. As such, our review work may be valuable for future research, as it provides a coherent and reproducible framework to assess the specificities and overlap between the four instruments (STAI, POMS, PANAS and VAS), which have been most commonly used in the literature to assess rapid changes in state anxiety in various situations and contexts.

\section{Acknowledgements}

This work is supported by a grant from the European Research Council (Starting Grant \#200758). We would like to thank Dr. Ernst Koster and two anonymous reviewers for their constructive comments on earlier draft of this manuscript.

\section{References}


Amir, N., Weber, G., Beard, C., Taylor, C. T., \& Bomyea, J. (2008). The effect of a singlesession attention modification program on response to a public-speaking challenge in socially anxious individuals. Journal of Abnormal Psychology, 117(4), 860-868. doi: $10.1037 / \mathrm{a} 0013445$

Andrykowski, M. A., \& Redd, W. H. (1987). Longitudinal analysis of the development of anticipatory nausea. Journal of Consulting and Clinical Psychology, 55(1), 36-41. doi: 10.1037/0022-006X.55.1.36

Andrykowski, M. A., Redd, W. H., \& Hatfield, A. K. (1985). Development of anticipatory nausea: A prospective analysis. Journal of Consulting and Clinical Psychology, 53(4), 447-454. doi: 10.1037/0022-006x.53.4.447

Bagozzi, R. P. (1993). An examination of the psychometric properties of measures of negative affect in the PANAS-X scales. Journal of Personality and Social Psychology, 65(4), 836-851. doi: 10.1037/0022-3514.65.4.836

Bolmont, B., \& Abraini, J. H. (2001). State-anxiety and low moods: Evidence for a single concept. Physiology \& Behavior, 74(4-5), 421-424. doi: 10.1016/S0031-9384(01)00575-3

Bonke, B., Smorenburg, J. M. J., Vanderent, C. K., \& Spielberger, C. D. (1987). Evidence of denial and item-intensity specificity in the State-Trait Anxiety Inventory. Personality and Individual Differences, 8(2), 185-191. doi: 10.1016/0191-8869(87)90173-5

Bruk-Lee, V., Khoury, H. A., Nixon, A. E., Goh, A., \& Spector, P. E. (2009). Replicating and Extending Past Personality/Job Satisfaction Meta-Analyses. Human Performance, 22(2), 156-189. doi: 10.1080/08959280902743709

Carlson, C. R., Collins, F. L., Stewart, J. F., Porzelius, J., Nitz, J. A., \& Lind, C. O. (1989). The assessment of emotional reactivity: A scale development and validation study. Journal of Psychopathology and Behavioral Assessment, 11, 313-325. doi: 10.1007/bf00961530

Carrillo, E., Moya-Albiol, L., Gonzalez-Bono, E., Salvador, A., Ricarte, J., \& Gomez-Amor, J. (2001). Gender differences in cardiovascular and electrodermal responses to public speaking task: the role of anxiety and mood states. International Journal of Psychophysiology, 42(3), 253-264. doi: 10.1016/s0167-8760(01)00147-7

Cattell, R. B. (1966). Patterns of change: Measurement in relation to state dimension, trait change, lability, and process concepts. In Handbook of Multivariate Experimental Psychology. Chicago: Rand McNally \& Co.

Cattell, R. B., \& Scheirer, I. H. (1958). The nature of anxiety: a review of thirteen multivariate analyses comprising 814 variables. Psychological Reports, 4, 351-388. doi: 10.2466/PR0.4.3.351-388

Cattell, R. B., \& Scheier, I. H. (1963). Handbook for the IPAT Anxiety Scale Questionnaire. Champaign IL: Institute for Personality and Ability Testing.

Caumo, W., Broenstrub, J. C., Fialho, L., Petry, S. M. G., Brathwait, O., Bandeira, D., et al. (2000). Risk factors for postoperative anxiety in children. Acta Anaesthesiologica Scandinavica, 44(7), 782-789. doi: 10.1034/j.1399-6576.2000.440703.x 
Cella, D. F., Jacobsen, P. B., Orav, E. J., Holland, J. C., Silberfarb, P. M., \& Rafla, S. (1987). A brief POMS measure of distress for cancer patients. Journal of Chronic Disease, 40, 939-942. doi: 10.1016/0021-9681(87)90143-3

Cella, D. F., \& Perry, S. W. (1986). Reliability and concurrent validity of three VisualAnalogue Mood Scales. Psychological Reports, 59, 827-833. doi: 10.2466/PR0.59.6.827833

Chlan, L. L. (2004). Relationship between two anxiety instruments in patients receiving mechanical ventilatory support. Journal of Advanced Nursing, 48(5), 493-499. doi: 10.1111/j.1365-2648.2004.03231.x

Chua, P., Krams, M., Toni, I., Passingham, R., \& Dolan, R. (1999). A functional anatomy of anticipatory anxiety. Neuroimage, 9(6), 563-571. doi: 10.1006/nimg.1999.0407

Cline, M. E., Herman, J., Shaw, E. R., \& Morton, R. D. (1992). Standardization of the Visual Analog Scale. Nursing Research, 41(6), 378-380.

Corah, N. L. (1969). Development of a dental anxiety scale. Journal of Dental Research, 48(4), 596. doi: 10.1177/00220345690480041801

Corchs, F., Nutt, D. J., Hood, S., \& Bernik, M. (2009). Serotonin and Sensitivity to TraumaRelated Exposure in Selective Serotonin Reuptake Inhibitors-Recovered Posttraumatic Stress Disorder. Biological Psychiatry, 66(1), 17-24. doi: 10.1016/j.biopsych.2009.01.031

Creamer, M., Foran, J., \& Bell, R. (1995). The Beck Anxiety Inventory in a nonclinical sample. Behaviour Research and Therapy, 33(4), 477-485. doi: 10.1016/00057967(94)00082-u

Curran, S. L., Andrykowski, M. A., \& Studts, J. L. (1995). Short Form of the Profile of Mood States (POMS-SF): Psychometric Information. Psychological Assessment, 7(1), 80-83. doi: $10.1037 / 1040-3590.7 .1 .80$

Davey, H. M., Barratt, A. L., Butow, P. N., \& Deeks, J. J. (2007). A one-item question with a Likert or Visual Analog Scale adequately measured current anxiety. Journal of Clinical Epidemiology, 60(4), 356-360. doi: 10.1016/j.jclinepi.2006.07.015

de Rooij, S. R., Schene, A. H., Phillips, D. I., \& Roseboom, T. J. (2010). Depression and anxiety: Associations with biological and perceived stress reactivity to a psychological stress protocol in a middle-aged population. Psychoneuroendocrinology, 35(6), 866-877. doi: 10.1016/j.psyneuen.2009.11.011

Elwood, L. S., \& Olatunji, B. O. (in press). Measurement of anxious traits: A contemporary review and synthesis. Anxiety, Stress and Coping: An International Journal.

Duncko, R., Makatsori, A., Fickova, E., Selko, D., \& Jezova, D. (2006). Altered coordination of the neuroendocrine response during psychosocial stress in subjects with high trait anxiety. Progress in Neuro-Psychopharmacology \& Biological Psychiatry, 30(6), 10581066. doi: 10.1016/j.pnpbp.2006.04.002

Freyd, M. (1923). The graphic rating scale. Journal of Educational Psychology, 14(2), 83102. doi: $10.1037 / \mathrm{h} 0074329$ 
Gift, A. G. (1989). Visual Analogue Scales: Measurement of subjective phenomena. Nursing Research, 38(5), 286-288.

Hamilton, M. (1959). The assessment of anxiety states by rating. British Journal of Medical Psychology, 32(1), 50-55.

Hornblow, A. R., \& Kidson, M. A. (1976). The visual analogue scale for anxiety: A validation study. Australian and New Zealand Journal of Psychiatry, 10(4), 339-341. doi: $10.3109 / 00048677609159523$

Kercher, K. (1992). Assessing subjective well-being in the old-old: the PANAS as a measure of orthogonal dimensions of positive and negative affect. Research on Aging, 14(2), 131168. doi: $10.1177 / 0164027592142001$

Kindler, C. H., Harms, C., Amsler, F., Ihde-Scholl, T., \& Scheidegger, D. (2000). The visual analog scale allows effective measurement of preoperative anxiety and detection of patients' anesthetic concerns. Anesthesia and Analgesia, 90(3), 706-712. doi: 10.1097/00000539-200003000-00036

Kirschbaum, C., Pirke, K. M., \& Hellhammer, D. H. (1993). The Trier Social Stress Test: A tool for investigating psychobiological stress responses in a laboratory setting. Neuropsychobiology, 28(1-2), 76-81. doi: 10.1159/000119004

Krane, V. (1994). The Mental readiness form as a measure of competitive state anxiety. The Sport Psychologist, 8(2), 189-202.

Lang, P. J., Davis, M., \& Ohman, A. (2000). Fear and anxiety: animal models and human cognitive psychophysiology. Journal of Affective Disorders, 61(3), 137-159. doi: 10.1016/s0165-0327(00)00343-8

Linden, M., Muschalla, B., \& Olbrich, D. (2008). Die Job-Angst-Skala (JAS): Entwicklung eines neuen Fragebogens zur Erfassung arbeitsplatzbezogener Ängste. Zeitschrift für Arbeits- und Organisationspsychologie, 52(3), 126-134. doi: 10.1026/0932-4089.52.3.126

Lucas, A., Holtmann, G., Gerken, G., Pietsch, A., Braun-Lang, U., Gilani, K., et al. (2006). Visceral pain and public speaking stress: Neuroendocrine and immune cell responses in healthy subjects. Brain Behavior and Immunity, 20(1), 49-56. doi: 10.1016/j.bbi.2005.03.009

Martens, R., Vealey, R., \& Burton, D. (1990). Competitive anxiety in sport. Champaign, IL: Human Kinetics.

McNair, D. M., \& Heuchert, J. P. (2005). Profile of Mood States: Technical update. Toronto, Canada: Multi-Health Systems.

McNair, D. M., Heuchert, J. P., \& Shilony, E. (2003). Research with the Profile of Mood States (POMS) 1964-2002: A comprehensive bibliography. Toronto, Canada: Multi-Health Systems.

McNair, D. M., Lorr, M., \& Droppleman, L. F. (1971). Manual: Profile of Mood States. San Diego, CA: Educational and Industrial Testing Service.

McNair, D. M., Lorr, M., \& Droppleman, L. F. (1992). Manual: Profile of Mood States, Revised 1992. San Diego, CA: Educational and Industrial Testing Service. 
Millar, K., Jelicic, M., Bonke, B., \& Asbury, A. J. (1995). Assessment of preoperative anxiety: Comparison of measures in patients awaiting surgery for breast-cancer. British Journal of Anaesthesia, 74(2), 180-183. doi: 10.1093/bja/74.2.180

Mineka, S., Watson, D., \& Clark, L. A. (1998). Comorbidity of anxiety and unipolar mood disorders. Annual Review of Psychology, 49, 377-412. doi: 10.1146/annurev.psych.49.1.377

Mitchell, A. J., Baker-Glenn, E. A., Granger, L., \& Symonds, P. (2010). Can the Distress Thermometer be improved by additional mood domains? Part I. Initial validation of the Emotion Thermometers tool. Psycho-Oncology, 19(2), 125-133. doi: 10.1002/pon.1523

Mitchell, A. J., Baker-Glenn, E. A., Park, B., Granger, L., \& Symonds, P. (2010). Can the Distress Thermometer be improved by additional mood domains? Part II. What is the optimal combination of Emotion Thermometers? Psycho-Oncology, 19(2), 134-140. doi: 10.1002/pon.1557

Moser, J. S., Hajcak, G., \& Simons, R. F. (2005). The effects of fear on performance monitoring and attentional allocation. Psychophysiology, 42(3), 261-268. doi: 10.1111/j.1469-8986.2005.00290.x

Norcross, J. C., Guadagnoli, E., \& Prochaska, J. O. (1984). Factor structure of the Profile of Mood States (POMS): Two partial replications. Journal of Clinical Psychology, 40(5), 1270-1277. doi: 10.1002/1097-4679(198409)40:5<1270::AID-JCLP2270400526>3.0.CO; $2-7$

Nyenhuis, D. L., Stern, R. A., Yamamoto, C., Luchetta, T., \& Arruda, J. E. (1997). Standardization and validation of the Visual Analog Mood Scales. Clinical Neuropsychologist, 11(4), 407-415. doi: 10.1080/13854049708400470

O'Brien, A., Terry, D. J., \& Jimmieson, N. L. (2008). Negative affectivity and responses to work stressors: An experimental study. Anxiety, Stress \& Coping: An International Journal, 21(1), 55-83. doi: 10.1080/10615800701529504

Perry, F., Parker, R. K., White, P. F., \& Clifford, P. A. (1994). Role of psychological factors in postoperative pain control and recovery with patient-controlled analgesia. Clinical Journal of Pain, 10(1), 57-63.

Pillard, R. C., Atkinson, K. W., \& Fisher, S. (1967). The effect of different preparations on film-induced anxiety. The Psychological Record, 17(1), 35-41.

Poma, S. Z., Milleri, S., Squassante, L., Nucci, G., Bani, M., Perini, G. I., et al. (2005). Characterization of a $7 \%$ carbon dioxide $(\mathrm{CO} 2)$ inhalation paradigm to evoke anxiety symptoms in healthy subjects. Journal of Psychopharmacology, 19(5), 494-503. doi: $10.1177 / 0269881105056533$

Shacham, S. (1983). A shortened version of the Profile of Mood States. Journal of Personality Assessment, 47, 305-306. doi: 10.1207/s15327752jpa4703_14

Smith, J. C. (1990). Cognitive-behavioral relaxation training: A new system of strategies for treatment and assessment. New York: Springer.

Spielberger, C. D. (1966). Theory and research on anxiety. In C. D. Spielberger (Ed.), Anxiety and behavior. New York: Academic Press. 
Spielberger, C. D. (1976). The nature and measurement of anxiety. In C. D. Spielberger \& R. Diaz-Guerrero (Eds.), Cross-cultural anxiety. Washington, DC: Hemisphere/Wiley.

Spielberger, C. D. (1983). Manual for the State-Trait Anxiety Inventory (Form Y) SelfEvaluation Questionnaire. Palo Alto, CA: Consulting Psychologists Press.

Spielberger, C. D. (1989). State-Trait Anxiety Inventory: A comprehensive bibliography. (Second Edition). . Palo Alto, CA: Consulting Psychologists Press.

Spielberger, C., Gorsuch, R. L., \& Lushene, R. E. (1970). Manual for the State-Trait Anxiety Inventory. Palo Alto, CA: Consulting Psychologists Press.

Spielberger, C. D., \& Reheiser, E. C. (2009). Assessment of Emotions: Anxiety, Anger, Depression, and Curiosity. Applied Psychology: Health and Well-Being, 1(3), 271-302. doi: 10.1111/j.1758-0854.2009.01017.x

Stern, R. A., Arruda, J. E., Hooper, C. R., Wolfner, G. D., \& Morey, C. E. (1997). Visual analogue mood scales to measure internal mood state in neurologically impaired patients: Description and initial validity evidence. Aphasiology, 11(1), 59-71. doi: $10.1080 / 02687039708248455$

Svebak, S., Ursin, H., Endresen, I., Hjelmen, A. M., \& Apter, M. J. (1991). Back pain and experience of stress, efforts and moods. Psychology and Health, 5, 307-314. doi: $10.1080 / 08870449108400431$

Swartzman, L. C., Edelberg, R., \& Kemmann, E. (1990). Impact of stress on objectively recorded menopausal hot flushes and on flush report bias. Health Psychology, 9(5), 529545. doi: 10.1037/0278-6133.9.5.529

Thompson, E. R. (2007). Development and validation of an internationally reliable shortform of the positive and negative affect schedule (Panas). Journal of Cross-Cultural Psychology, 38(2), 227-242. doi: 10.1177/0022022106297301

Vagg, P. R., Spielberger, C. D., \& O’Hearn, T. P. (1980). Is the State-Trait Anxiety Inventory multidimensional? Personality and Individual Differences, 1(3), 207-214. doi: 10.1016/0191-8869(80)90052-5

van Duinen, M., Rickelt, J., \& Griez, E. (2008). Validation of the electronic visual analogue scale of anxiety. Progress in Neuro-Psychopharmacology \& Biological Psychiatry, 32(4), 1045-1047. doi: 10.1016/j.pnpbp.2008.02.002

Vogelsang, J. (1988). The Visual Analog Scale: an accurate and sensitive method for selfreporting preoperative anxiety. Journal of Post Anesthesia Nursing, 3(4), 235-239.

Watson, D., \& Clark, L. A. (1991). Self-ratings Versus Peer-ratings of Specific Emotional Traits: Evidence of Convergent and Discriminant Validity. Journal of Personality and Social Psychology, 60(6), 927-940. doi: 10.1037/0022-3514.60.6.927

Watson, D., \& Clark, L. A. (1992). Affects Separable and Inseparable: On the Hierarchical Arrangement of the Negative Affects. Journal of Personality and Social Psychology, 62(3), 489-505. doi: 10.1037/0022-3514.62.3.489

Watson, D., \& Clark, L. A. (1994). The PANAS-X manual for the Positive and Negative Affect Schedule-Expanded Form. (Unpublished manuscript, University of Iowa). 
Watson, D., Clark, L. A., \& Tellegen, A. (1988). Development and validation of brief measures of positive and negative affect: the PANAS scales. Journal of Personality and Social Psychology, 54(6), 1063-1070. doi: 10.1037/0022-3514.54.6.1063

Wolitzky-Taylor, K. B., Castriotta, N., Lenze, E. J., Stanley, M. A., \& Craske, M. G. (2010). Anxiety disorders in older adults: a comprehensive review. Depression and Anxiety, 27(2), 190-211. doi: 10.1002/da.20653

Wolpe, J. (1958). Psychotherapy by reciprocal inhibition. Stanford, CA: Stanford University Press.

Wolpe, J. (1990). The practice of behavior therapy (4th ed.). New York: Pergamon Press.

Zigmond, A. S., \& Snaith, R. P. (1983). The Hospital Anxiety and Depression Scale. Acta Psychiatrica Scandinavica, 67(6), 361-370. doi: 10.1111/j.1600-0447.1983.tb09716.x

Zuckerman, M., \& Lubin, B. (1985). Manual for the Revised Multiple Affect Adjective Check List. San Diego, CA: EDITS. 


\begin{tabular}{|c|c|c|c|c|c|c|c|c|c|c|c|c|}
\hline. $\mathrm{N}$ & Reference & $\begin{array}{l}\text { STAI } \\
\text { State }\end{array}$ & POMS & PANAS & VAS & Other & Construct & Domain & Population & Manipulation & $\begin{array}{l}\text { Direction of the } \\
\text { Effect }\end{array}$ & Approach \\
\hline 1 & Abdul-Latif et al., 2001 & $\mathrm{x}$ & & & $\mathrm{x}$ & & Anx & $\operatorname{Tr}$ & Clinical & Central & Regulation & Causal \\
\hline 2 & Abercrombie, Kalin, \& Davidson, 2005 & & & $\mathrm{x}$ & & $\mathrm{x}$ & Aff & Exp & Non clinical & Central & Induction & Descriptive \\
\hline 3 & Abrams et al., 1987 & $\mathrm{x}$ & & & $\mathrm{x}$ & & Anx & Exp & Non clinical & Central & Induction & Causal \\
\hline 4 & Abrams et al., 2002 & $\mathrm{x}$ & & & $\mathrm{x}$ & & Anx & Exp & Clinical & Central & Induction & Causal \\
\hline 5 & Amir et al., 2008 & $\mathrm{x}$ & & & & & Anx & $\operatorname{Tr}$ & Non clinical & Central & Ind/Reg & Causal \\
\hline 6 & Andrykowski, \& Redd, 1987 & & & & $\mathrm{x}$ & & Anx & Applied & Clinical & No manipulation & & Descriptive \\
\hline 7 & Andrykowski, Redd, \& Hatfield, 1985 & & & & $\mathrm{x}$ & & Anx & Applied & Clinical & No manipulation & & Descriptive \\
\hline 8 & Aragon, Farris, \& Byers, 2002 & & & & $\mathrm{x}$ & & Anx & $\operatorname{Tr}$ & Clinical & Central & Regulation & Causal \\
\hline 9 & Arent et al., 2005 & $\mathrm{x}$ & & $\mathrm{x}$ & & & Aff & Exp & Non clinical & Peripheral & Regulation & Causal \\
\hline 10 & Argyropoulos et al., 2004 & $\mathrm{x}$ & & & $\mathrm{x}$ & & Anx & Exp & Clinical & Central & Induction & Causal \\
\hline 11 & Arizono et al., 2000 & $\mathrm{x}$ & & & $\mathrm{x}$ & & Anx & $\operatorname{Tr}$ & Clinical & Central & Regulation & Causal \\
\hline 12 & Arntz, Merckelbach, \& de Jong, 1993 & & & & $\mathrm{x}$ & & Anx & Exp & Clinical & Central & Ind/Reg & Causal \\
\hline 13 & Auquier et al., 1995 & $\mathrm{x}$ & & & & & Anx & Applied & Clinical & No manipulation & & Descriptive \\
\hline 14 & Baker, \& Guttfreund, 1993 & $\mathrm{x}$ & & & & & Anx/Mood & Exp & Non clinical & Central & Induction & Causal \\
\hline 15 & Baron, Logan, \& Hoppe, 1993 & $\mathrm{x}$ & & & $\mathrm{x}$ & & Anx & $\operatorname{Tr}$ & Non clinical & Central & Regulation & Causal \\
\hline 16 & Bartholomew, Morrison, \& Ciccolo,2005 & & $\mathrm{x}$ & & & & Mood/Aff & $\operatorname{Tr}$ & Clinical & Peripheral & Regulation & Causal \\
\hline 17 & Benedetti et al., 2003 & $\mathrm{x}$ & & & & & Anx & Exp & Clinical & Central & Regulation & Descriptive \\
\hline 18 & Benotsch et al., 2000 & $\mathrm{x}$ & & & $\mathrm{x}$ & & Anx & Exp & Clinical & No manipulation & & descriptive \\
\hline 19 & Bernat et al., 2001 & $\mathrm{x}$ & & $\mathrm{x}$ & & & Anx & Exp & Non clinical & Central & Induction & Descriptive \\
\hline 20 & Bixby, Spalding, \& Hatfield, 2001 & & & $\mathrm{x}$ & $\mathrm{x}$ & & Mood/Aff & Exp & Non clinical & Peripheral & Regulation & Causal \\
\hline 21 & Bodin, \& Martinsen, 2004 & $\mathrm{x}$ & & $\mathrm{x}$ & & & Anx & $\operatorname{Tr}$ & Clinical & Peripheral & Regulation & Causal \\
\hline 22 & Bogaerts et al., 2010 & & & & $\mathrm{x}$ & & Anx & Exp & Clinical & Peripheral & Induction & Causal \\
\hline 23 & Bond, Shine, \& Bruce, 1995 & $\mathrm{x}$ & & & $\mathrm{x}$ & & Anx & Exp & Non clinical & Central & Induction & Causal \\
\hline 24 & Bowen et al., 2006 & & & & $\mathrm{x}$ & & Anx & Applied & Clinical & No manipulation & & Descriptive \\
\hline 25 & Bradley et al., 2009 & $\mathrm{x}$ & & $\mathrm{x}$ & & & Anx & $\operatorname{Tr}$ & Non clinical & Peripheral & Regulation & Causal \\
\hline 26 & Bringman et al., 2009 & $\mathrm{x}$ & & & & & Anx & $\operatorname{Tr}$ & Clinical & Central & Regulation & Causal \\
\hline 27 & Bringuier et al., 2009 & $\mathrm{x}$ & & & $\mathrm{x}$ & & Anx & Applied & Clinical & No manipulation & & Descriptive \\
\hline 28 & Britt et al., 2001 & $\mathrm{x}$ & & & & EAS & Anx & Exp & Non clinical & Central & Ind/Reg & Causal \\
\hline 29 & Bruera et al., 2008 & $\mathrm{x}$ & & & & & Anx & $\operatorname{Tr}$ & Clinical & Central & Regulation & Causal \\
\hline 30 & Bruning, \& McMahon, 2009 & $\mathrm{x}$ & & $\mathrm{x}$ & & & Anx/Mood & Exp & Non clinical & Central & Induction & Causal \\
\hline 31 & Buckelew et al., 1992 & $\mathrm{x}$ & & & $\mathrm{x}$ & & Anx & Applied & Clinical & No manipulation & & Descriptive \\
\hline 32 & Campeau et al., 2007 & & & & $\mathrm{x}$ & & Anx & $\operatorname{Tr}$ & Clinical & Peripheral & Regulation & Causal \\
\hline 33 & Carrillo et al., 2001 & $\mathrm{x}$ & $\mathrm{x}$ & & & & Anx & Exp & Non clinical & Central & Induction & Causal \\
\hline 34 & Carter et al., 1995 & $\mathrm{x}$ & & & & & Anx & Exp & Clinical & Central & Ind/Reg & Causal \\
\hline 35 & Caumo et al., 2000 & $\mathrm{x}$ & & & & & Anx & Exp & Clinical & No manipulation & & Descriptive \\
\hline 36 & Chan et al., 2003 & $\mathrm{x}$ & & & & & Anx & $\operatorname{Tr}$ & Clinical & Central & Regulation & Causal \\
\hline 37 & Chua et al., 1999 & $\mathrm{x}$ & & & $\mathrm{x}$ & & Anx & Exp & Non clinical & Central & Ind/Reg & Causal \\
\hline 38 & Cinciripini et al., 2006 & & & & & $\mathrm{x}$ & Aff/Mood & Exp & Non clinical & Central & Induction & descriptive \\
\hline 39 & Clark, \& Golshan, 2008 & $\mathrm{x}$ & & & & & Anx & $\operatorname{Tr}$ & Clinical & Peripheral & Regulation & Causal \\
\hline 40 & Cools et al., 2005 & & & $\mathrm{x}$ & $\mathrm{x}$ & & Anx/Mood & Exp & Non clinical & Central & Induction & Descriptive \\
\hline 41 & Corchs et al., 2009 & $\mathrm{x}$ & $\mathrm{x}$ & & $\mathrm{x}$ & HAM-A & Anx & Exp & Clinical & Central & Induction & Causal \\
\hline 42 & Cruise et al., 1997 & $\mathrm{x}$ & & & & & Anx & $\operatorname{Tr}$ & Clinical & Central & Regulation & Causal \\
\hline 43 & Daley, \& Maynard, 2003 & & & $\mathrm{x}$ & & & Aff & Exp & Non clinical & Peripheral & Regulation & Descriptive \\
\hline 44 & de-Paris et al., 2003 & & $\mathrm{x}$ & & $\mathrm{x}$ & & Anx & Exp & Non clinical & Central & Ind/Reg & Causal \\
\hline 45 & Diego et al., 1998 & $\mathrm{x}$ & $\mathrm{x}$ & & $\mathrm{x}$ & & Anx & $\operatorname{Tr}$ & Non clinical & Peripheral & Regulation & Causal \\
\hline 46 & Donoyama, Munakata, \& Shibasaki, 2010 & $\mathrm{x}$ & & & & & Anx & $\operatorname{Tr}$ & Non clinical & Peripheral & Regulation & Causal \\
\hline 47 & Duka et al., 1988 & $\mathrm{x}$ & & & & & Anx & Exp & Non clinical & Central & Regulation & Descriptive \\
\hline 48 & Durkin, \& Paxton, 2002 & & & & $\mathrm{x}$ & & Anx & Exp & Non clinical & Central & Induction & Causal \\
\hline 49 & Edwards, Burt, \& Lipp, 2010 & & & & & ARQ & Anx & Exp & Non clinical & Central & Induction & Causal \\
\hline 50 & Ekwall, Gerdtz,\& Manias, 2009 & & & & $\mathrm{x}$ & & Anx & Applied & Non Clinical & No manipulation & & Descriptive \\
\hline 51 & Erb et al., 1998 & $\mathrm{x}$ & & & & & Anx & $\operatorname{Tr}$ & Clinical & Central & Regulation & Causal \\
\hline 52 & Eubank, Collins, \& Smith, 2002 & & & $\mathrm{x}$ & & & Anx & Exp & Non clinical & Central & Induction & descriptive \\
\hline 53 & Ferrer-Garcia, \& Gutiérrez Maldonado, 2005 & $x$ & & & & & Anx & Exp & Clinical & Central & Induction & Causal \\
\hline 54 & Field et al., 1996 & $\mathrm{x}$ & $\mathrm{x}$ & & & & Anx & $\operatorname{Tr}$ & Non clinical & Peripheral & Regulation & Causal \\
\hline 55 & Focht, \& Koltyn, 1999 & $\mathrm{x}$ & $\mathrm{x}$ & & & & Anx & $\operatorname{Tr}$ & Non clinical & Peripheral & Regulation & Causal \\
\hline 56 & Fox et al., 2001 & $\mathrm{x}$ & & & & & Anx & Exp & Non clinical & Central & Induction & Causal \\
\hline 57 & Fumoto et al., 2004 & $\mathrm{x}$ & $\mathrm{x}$ & & & & Anx & $\operatorname{Tr}$ & Non clinical & Peripheral & Regulation & Causal \\
\hline 58 & Garvin, \& Damson, 2008 & $\mathrm{x}$ & $\mathrm{x}$ & & & & Anx & Exp & Non clinical & Central & Induction & Descriptive \\
\hline
\end{tabular}




\begin{tabular}{|c|c|c|c|c|c|c|c|c|c|c|c|c|}
\hline. $\mathrm{N}$ & Reference & $\begin{array}{l}\text { STAI } \\
\text { State }\end{array}$ & POMS & PANAS & VAS & Other & Construct & Domain & Population & Manipulation & $\begin{array}{l}\text { Direction of the } \\
\text { Effect }\end{array}$ & Approach \\
\hline 59 & Gaudreau, Blondin, \& Lapierre, 2002 & & & $\mathrm{x}$ & & & Aff & Applied & Non clinical & Peripheral & No Manipulation & Descriptive \\
\hline 60 & Geeraerts et al., 2005 & $\mathrm{x}$ & & & $\mathrm{x}$ & & Anx & Exp & Non clinical & Central & Induction & Causal \\
\hline 61 & Gejervall et al., 2005 & $\mathrm{x}$ & & & $\mathrm{x}$ & & Anx & $\operatorname{Tr}$ & Clinical & Peripheral & Regulation & Descriptive \\
\hline 62 & Gilbert, Parker, \& Claiborn, 1978 & & $\mathrm{x}$ & & & & Anx & $\operatorname{Tr}$ & Clinical & Central & Regulation & Causal \\
\hline 63 & Goldin et al., 2009 & & & & $\mathrm{x}$ & & Aff & Exp & Clinical & Central & Induction & Causal \\
\hline 64 & Grasing et al., 1996 & $\mathrm{x}$ & $\mathrm{x}$ & & $\mathrm{x}$ & & Anx/Mood/Aff & Exp & Non clinical & Central & Induction & Descriptive \\
\hline 65 & Grassi, Gaggioli, \& Riva, 2009 & $\mathrm{x}$ & & $\mathrm{x}$ & $\mathrm{x}$ & & Anx & $\operatorname{Tr}$ & Non clinical & Central & Regulation & Causal \\
\hline 66 & Grillon et al., 2003 & $\mathrm{x}$ & & $\mathrm{x}$ & $\mathrm{x}$ & & Anx & $\operatorname{Tr}$ & Non clinical & Central & Ind/Reg & Causal \\
\hline 67 & Gutierrez-Maldonado et al., 2006 & $\mathrm{x}$ & & & & & Anx & Exp & Clinical & Central & Induction & Causal \\
\hline 68 & Hale, \& Raglin, 2002 & $\mathrm{x}$ & & & & & Anx & $\operatorname{Tr}$ & Non clinical & Peripheral & Regulation & Causal \\
\hline 69 & Hatayama et al., 2008 & $\mathrm{x}$ & $\mathrm{x}$ & & & & Anx/Mood & $\operatorname{Tr}$ & Non clinical & Peripheral & Regulation & Causal \\
\hline 70 & Hayasaka et al., 2008 & $\mathrm{x}$ & $\mathrm{x}$ & & & & Anx/Mood & $\operatorname{Tr}$ & Non clinical & Peripheral & Regulation & Causal \\
\hline 71 & Hayasaka et al., 2009 & $\mathrm{x}$ & $\mathrm{x}$ & & & & Anx/Mood & $\operatorname{Tr}$ & Non clinical & Peripheral & Regulation & Causal \\
\hline 72 & Head et al., 1996 & $\mathrm{x}$ & $\mathrm{x}$ & & & & Anx/Mood & Exp & Non clinical & Central & Ind/Reg & Causal \\
\hline 73 & Heikkila et al., 1998 & $\mathrm{x}$ & & & $\mathrm{x}$ & HADS-A & Fear & Applied & Clinical & No manipulation & & Descriptive \\
\hline 74 & Hofer et al., 2003 & $\mathrm{x}$ & & & & & Anx & Exp & Clinical & Central & Regulation & Descriptive \\
\hline 75 & Holmes, Lang, \& Shah, 2009 & $\mathrm{x}$ & & $\mathrm{x}$ & & & Anx & $\operatorname{Tr}$ & Non clinical & Central & Ind/Reg & Causal \\
\hline 76 & Holmes, \& Mathews, 2005 & $\mathrm{x}$ & & & & & Anx & Exp & Non clinical & Central & Induction & Causal \\
\hline 77 & Holmes et al., 2008 & $\mathrm{x}$ & & & & & Anx/Aff & Exp & Non clinical & Central & Ind/Reg & Causal \\
\hline 78 & Hood et al., 2010 & $\mathrm{x}$ & $\mathrm{x}$ & & $\mathrm{x}$ & & Anx & Exp & Clinical & Central & Induction & Causal \\
\hline 79 & Hood et al., 2006 & $\mathrm{x}$ & & & $\mathrm{x}$ & & Anx & Exp & Non clinical & Central & Induction & Causal \\
\hline 80 & Hopko, Hunt, \& Armento, 2005 & & & & $\mathrm{x}$ & & Anx & Exp & Non clinical & Central & Induction & Causal \\
\hline 81 & Hughes, \& Kendall, 2008 & & & & & SUDS & Anx & Exp & Clinical & Central & Regulation & Descriptive \\
\hline 82 & Ihme, \& Mitte, 2009 & $\mathrm{x}$ & & & & & Fear & Exp & Non clinical & Central & Induction & Descriptive \\
\hline 83 & Iizawa et al., 2004 & $\mathrm{x}$ & & & & & Anx & $\operatorname{Tr}$ & Clinical & Central & Regulation & Causal \\
\hline 84 & Imura, Misao, \& Ushijima, 2006 & $\mathrm{x}$ & $\mathrm{x}$ & & & & Anx/Mood & $\operatorname{Tr}$ & Non clinical & Peripheral & Regulation & Causal \\
\hline 85 & Jacobsen et al., 1995 & & & & $\mathrm{x}$ & & Anxiety/Distress & Exp & Clinical & Central & Induction & Causal \\
\hline 86 & Järvekülg, 2005 & $\mathrm{x}$ & & $\mathrm{x}$ & & & Anx/Aff & Exp & Non clinical & Peripheral & Regulation & Descriptive \\
\hline 87 & Järvekülg, Neissaar, \& Viru, 2001 & $\mathrm{x}$ & & $\mathrm{x}$ & & & Anx & Exp & Non clinical & Peripheral & Regulation & Descriptive \\
\hline 88 & Jerabek et al., 1998 & $\mathrm{x}$ & & & & & Anx & Exp & Non clinical & Central & Induction & Causal \\
\hline 89 & Johansson, Hassmén, \& Jouper, 2008 & $\mathrm{x}$ & $\mathrm{x}$ & & & & Anx/Mood & $\operatorname{Tr}$ & Non clinical & Peripheral & Regulation & Causal \\
\hline 90 & Juliano, Brandon, \& Moffitt, 2002 & $\mathrm{x}$ & & & & & Anx & Exp & Non clinical & Central & Ind/Reg & Descriptive \\
\hline 91 & Kagaya et al., 2001 & & $\mathrm{x}$ & & & & Anx & $\operatorname{Tr}$ & Clinical & Central & Regulation & Descriptive \\
\hline 92 & Kassel, \& Unrod, 2000 & $\mathrm{x}$ & & & & & Anx & Exp & Non clinical & Central & Ind/Reg & Causal \\
\hline 93 & Kennedy, \& Newton, 1997 & & $\mathrm{x}$ & & & & Mood & $\operatorname{Tr}$ & Non clinical & Peripheral & Regulation & Causal \\
\hline 94 & Kerr et al., 2005 & & & & & TESI & Anx & Applied & Non clinical & No Manipulation & & Descriptive \\
\hline 95 & Kimberger, Illievich, \& Lenhardt, 2007 & $\mathrm{x}$ & & & $\mathrm{x}$ & & Anx & $\operatorname{Tr}$ & Clinical & Peripheral/Central & Regulation & Causal \\
\hline 96 & Koukounas, \& McCabe, 2001 & & & & $\mathrm{x}$ & & Anx & Exp & Non clinical & Central & Induction & Descriptive \\
\hline 97 & Kraemer, \& Marquez, 2009 & $\mathrm{x}$ & & $\mathrm{x}$ & & & Anx/Mood & $\operatorname{Tr}$ & Non clinical & Peripheral & Regulation & Causal \\
\hline 98 & Kreutz et al., 2004 & & & $\mathrm{x}$ & & & Aff & $\operatorname{Tr}$ & Non clinical & Central & Regulation & Causal \\
\hline 99 & Krueger et al., 2005 & $\mathrm{x}$ & & & $\mathrm{x}$ & & Anx & Exp & Clinical & Central & Induction & Descriptive \\
\hline 100 & Laidlaw et al., 2006 & $\mathrm{x}$ & $\mathrm{x}$ & & & & Anx & $\operatorname{Tr}$ & Non clinical & Central & Ind/Reg & Causal \\
\hline 101 & Law, Logan, \& Baron, 1994 & $\mathrm{x}$ & & & $\mathrm{x}$ & & Anx & $\operatorname{Tr}$ & Non clinical & Central & Regulation & Causal \\
\hline 102 & LeBlanc et al., 2008 & $\mathrm{x}$ & & & & & Anx/Stress & Exp & Non clinical & Central & Induction & Descriptive \\
\hline 103 & Lepage et al., 2001 & $\mathrm{x}$ & & & $\mathrm{x}$ & & Anx & $\operatorname{Tr}$ & Clinical & Central & Regulation & Causal \\
\hline 104 & Li et al., 2000 & $\mathrm{x}$ & $\mathrm{x}$ & & & & Anx/Mood & Exp & Non clinical & Central & Induction & Causal \\
\hline 105 & Liotti et al., 2000 & & & & $\mathrm{x}$ & & Anx & Exp & Non clinical & Central & Induction & Causal \\
\hline 106 & Litvin, \& Brandon, 2010 & $\mathrm{x}$ & & & & $\mathrm{x}$ & Anx & Exp & Non clinical & Central & Induction & Descriptive \\
\hline 107 & Liu et al., 2005 & & $\mathrm{x}$ & & & & Mood & $\operatorname{Tr}$ & Non clinical & Peripheral & Regulation & Causal \\
\hline 108 & Lu et al., 2004 & $\mathrm{x}$ & & & $\mathrm{x}$ & BAI & Anx & $\operatorname{Tr}$ & Non clinical & Central & Ind/Reg & Causal \\
\hline 109 & Lucas et al., 2006 & $\mathrm{x}$ & & & & & Anx/Stress & Exp & Non clinical & Central & Induction & Causal \\
\hline 110 & Man et al., 2003 & $\mathrm{x}$ & & & $\mathrm{x}$ & & Anx & $\operatorname{Tr}$ & Clinical & Central & Regulation & Causal \\
\hline 111 & Martelli et al., 1987 & $\mathrm{x}$ & & & & & Anx & $\operatorname{Tr}$ & Clinical & Central & Regulation & Causal \\
\hline 112 & Masdrakis et al., 2009 & $\mathrm{x}$ & & & $\mathrm{x}$ & & Anx & Exp & Clinical & Central & Induction & Causal \\
\hline 113 & Masters et al., 2003 & $\mathrm{x}$ & $\mathrm{x}$ & & & & Anx/Aff & Exp & Non clinical & Peripheral & Regulation & Causal \\
\hline 114 & Mathews,\& Mackintosh, 2000 & $\mathrm{x}$ & & & & & Anx & Exp & Non clinical & Central & Induction & Causal \\
\hline 115 & McDermut, \& Haaga, 1998 & & & $\mathrm{x}$ & & & Aff & Exp & Non clinical & Central & Induction & Causal \\
\hline 116 & Meinberg, \& Yager, 1985 & $\mathrm{x}$ & & & & & Anx & Exp & Non clinical & Central & Regulation & Descriptive? \\
\hline 117 & Mendonca-de-Souza et al., 2007 & & & $\mathrm{x}$ & & & Anx/Stress & Exp & Non clinical & Central & Induction & Causal \\
\hline
\end{tabular}




\begin{tabular}{|c|c|c|c|c|c|c|c|c|c|c|c|c|}
\hline. $\mathrm{N}$ & Reference & $\begin{array}{l}\text { STAI } \\
\text { State }\end{array}$ & POMS & PANAS & VAS & Other & Construct & Domain & Population & Manipulation & $\begin{array}{l}\text { Direction of the } \\
\text { Effect }\end{array}$ & Approach \\
\hline 118 & Mercer, Warson, \& Zhao, 2010 & $\mathrm{x}$ & & $\mathrm{x}$ & & & Anx & $\operatorname{Tr}$ & Non clinical & Central & Regulation & Causal \\
\hline 119 & Merckaert et al., 2009 & $\mathrm{x}$ & & & & & Anx & Exp & Clinical & Central & Induction & Descriptive \\
\hline 120 & Miller, Bartholomew, \& Springer, 2005 & & & $\mathrm{x}$ & & & Aff & $\operatorname{Tr}$ & Non clinical & Peripheral & Regulation & Causal \\
\hline 121 & Miller, Taylor, \& Tinklenberg, 1988 & & $\mathrm{x}$ & & $\mathrm{x}$ & & Mood & Exp & Non clinical & Central & Regulation & Descriptive \\
\hline 122 & Mitchell, MacDonald, \& Knussen,2008 & $\mathrm{x}$ & & & & & Anx & $\operatorname{Tr}$ & Non clinical & Central & Ind/Reg & Causal \\
\hline 123 & Modena et al., 1989 & $\mathrm{x}$ & & & & & Anx & Exp & Clinical & Central & Induction & Causal \\
\hline 124 & Moser, Hajcak, \& Simons, 2005 & & & & & SUDS & Anx & Exp & Clinical & Central & Induction & Descriptive \\
\hline 125 & Munafo, Hayward, \& Harmer, 2006 & & $\mathrm{x}$ & & $\mathrm{x}$ & & Anx & Exp & Clinical & Central & Induction & Causal \\
\hline 126 & Muzzarelli,Force, \& Sebold, 2006 & $\mathrm{x}$ & & & & & Anx & $\operatorname{Tr}$ & Clinical & Peripheral & Regulation & Causal \\
\hline 127 & Nainis et al., 2006 & $\mathrm{x}$ & & & & & Anx & $\operatorname{Tr}$ & Clinical & Central & Regulation & Causal \\
\hline 128 & Nakane et al., 2002 & $\mathrm{x}$ & & & & & Anx/Stress & $\operatorname{Tr}$ & Non clinical & Central & Ind/Reg & Causal \\
\hline 129 & Neissaar et al., 2002 & $\mathrm{x}$ & & $\mathrm{x}$ & & & Anx & $\operatorname{Tr}$ & Non clinical & Peripheral & Regulation & Descriptive \\
\hline 130 & Noto et al., 2005 & $\mathrm{x}$ & & & & & Anx/Stress & Exp & Non clinical & Central & Induction & Descriptive \\
\hline 131 & O'Brien, Terry, \& Jimmieson,2008 & & $\mathrm{x}$ & & & & Anx/Mood/Aff & Exp & Non clinical & Central & Induction & Causal \\
\hline 132 & O'Halloran, Murphy, \& Webster, 2004 & & $\mathrm{x}$ & & & & Mood & $\operatorname{Tr}$ & Non clinical & Peripheral & Regulation & Causal \\
\hline 133 & Okawa, Ichinohe, \& Kaneko, 2005 & & & & $\mathrm{x}$ & & Anx & Exp & Non clinical & Central & Induction & Causal \\
\hline 134 & Oldman, Moore, \& Collins, 2004 & $\mathrm{x}$ & & & $\mathrm{x}$ & & Anx & Exp & Clinical & Central & Regulation & Descriptive \\
\hline 135 & Oliveira, Gouveia, \& Oliveira, 2009 & & $\mathrm{x}$ & & & MRT & Anx/Mood & Applied & Non clinical & No Manipulation & & Descriptive \\
\hline 136 & Park et al., 2009 & $\mathrm{x}$ & & $\mathrm{x}$ & & & Anx & Exp & Clinical & Central & Induction & Causal \\
\hline 137 & Parr, \& Cartwright-Hatton, 2009 & $\mathrm{x}$ & & & & & Anx & $\operatorname{Tr}$ & Subclinical & Central & Ind/Reg & Causal \\
\hline 138 & Perry et al., 1994 & & & & $\mathrm{x}$ & & Anx & Exp & Clinical & No manipulation & & Descriptive \\
\hline 139 & Perry et al., 1990 & & & & $\mathrm{x}$ & & Anx & Applied & Clinical & No manipulation & & Descriptive \\
\hline 140 & Petruzzello et al., 2009 & $\mathrm{x}$ & $\mathrm{x}$ & & $\mathrm{x}$ & & Anx/Mood & $\operatorname{Tr}$ & Clinical & Peripheral & Regulation & Causal \\
\hline 141 & Philippot, Baeyens, \& Douilliez, 2006 & $\mathrm{x}$ & & & & & Anx & $\operatorname{Tr}$ & Non clinical & Central & Regulation & Causal \\
\hline 142 & Phillips, \& Giancola, 2008 & & & $\mathrm{x}$ & & & Anx & Exp & Non clinical & Central & Induction & Causal \\
\hline 143 & Polman et al., 2007 & & $\mathrm{x}$ & & $\mathrm{x}$ & & Mood & Applied & Non clinical & No Manipulation & & Descriptive \\
\hline 144 & Poma et al., 2005 & $\mathrm{x}$ & & & $\mathrm{x}$ & & Anx & Exp & Non clinical & Central & Induction & Causal \\
\hline 145 & Prabhu et al., 2009 & $\mathrm{x}$ & & & $\mathrm{x}$ & & Anx & $\operatorname{Tr}$ & Clinical & Central & Regulation & Descriptive \\
\hline 146 & Rabe et al., 2006 & & & $\mathrm{x}$ & & & Anx & Exp & Clinical & Central & Induction & Causal \\
\hline 147 & Raes et al., 2003 & $\mathrm{x}$ & & & $\mathrm{x}$ & & Anx & Exp & Non clinical & Central & Induction & Descriptive \\
\hline 148 & Raglin, \& Wilson, 1996 & $\mathrm{x}$ & & & & & Anx & $\operatorname{Tr}$ & Non clinical & Peripheral & Regulation & Causal \\
\hline 149 & Rausch, Gramling, \& Auerbach, 2006 & $\mathrm{x}$ & & & & SSSSS-S & Anx & $\operatorname{Tr}$ & Non clinical & Central & Regulation & Causal \\
\hline 150 & Redd et al., 1987 & & & & $\mathrm{x}$ & & Anx & $\operatorname{Tr}$ & Clinical & Central & Regulation & Causal \\
\hline 151 & Reinecke, Rinck, \& Becker, 2006 & $\mathrm{x}$ & & & & & Anx & Exp & Clinical & Central & Induction & Descriptive \\
\hline 152 & Rejeski et al., 1995 & & & $\mathrm{x}$ & & & Aff & $\operatorname{Tr}$ & Non clinical & Peripheral & Regulation & Causal \\
\hline 153 & Ren et al., 2009 & & & & $\mathrm{x}$ & & Anx & Exp & Clinical & Central & Induction & Causal \\
\hline 154 & Rinck et al., 2005 & $\mathrm{x}$ & & & & & Anx & Exp & Subclinical & Central & Induction & Descriptive \\
\hline 155 & Robb, 2000 & $\mathrm{x}$ & & & $\mathrm{x}$ & & Anx & $\operatorname{Tr}$ & Non clinical & Central & Regulation & Causal \\
\hline 156 & Rodebaugh et al., 2009 & $x$ & & $\mathrm{x}$ & & & Anx/Mood & $\operatorname{Tr}$ & Subclinical & Central & Ind/Reg & Causal \\
\hline 157 & Rogers, \& Revelle, 1998 & & & & & MSQ-R & Mood & Exp & Non clinical & Central & Ind/Reg & Descriptive \\
\hline 158 & Rosa et al., 2004 & & $\mathrm{x}$ & & & & Anx/Mood & Exp & Non clinical & Peripheral & Regulation & Descriptive \\
\hline 159 & Ruijter et al., 2000 & $\mathrm{x}$ & $\mathrm{x}$ & & & & Anx/Mood & Exp & Non clinical & Central & Induction & Descriptive \\
\hline 160 & Ruijter, Lorist, \& Snel, 1999 & $\mathrm{x}$ & $\mathrm{x}$ & & & & Anx/Mood & Exp & Non clinical & Central & Induction & Descriptive \\
\hline 161 & Sablowski, \& Herrmann, 1986 & $\mathrm{x}$ & & & & & Anx & Applied & Clinical & No manipulation & & Descriptive \\
\hline 162 & Schmid-Leuz et al., 2007 & & & & & SUDS & Anx & $\operatorname{Tr}$ & Non clinical & Central & Ind/Reg & Causal \\
\hline 163 & Schneider et al., 2003 & $\mathrm{x}$ & & & & & Anx & $\operatorname{Tr}$ & Clinical & Central & Regulation & Causal \\
\hline 164 & Schunck et al., 2008 & $\mathrm{x}$ & & & $\mathrm{x}$ & HAM-A & Anx & Exp & Non clinical & Central & Induction & Causal \\
\hline 165 & Schwerdtfeger, Schmukle, \& Egloff, 2006 & & & & $\mathrm{x}$ & & Aff & Exp & Non clinical & Central & Induction & Causal \\
\hline 166 & Scott, McNaughton, \& Polman, 2006 & & $\mathrm{x}$ & & & & Anx & Exp & Non clinical & Sleep deprivation & & Descriptive \\
\hline 167 & Shioiri et al., 2006 & $\mathrm{x}$ & & & & & Anx & Exp & Clinical & Central & Induction & Descriptive \\
\hline 168 & Sideridis, 2008 & & & $\mathrm{x}$ & & & Anx & Exp & Non clinical & Central & Induction & Descriptive \\
\hline 169 & Simpson et al., 2008 & & & $\mathrm{x}$ & & & Mood/Aff & Applied & Non clinical & No manipulation & & Descriptive \\
\hline 170 & Slaven, \& Lee, 1997 & & $\mathrm{x}$ & & & & Mood & Exp & Non clinical & Peripheral & Regulation & Descriptive \\
\hline 171 & Starcke et al., 2008 & $\mathrm{x}$ & & $\mathrm{x}$ & & & Anx/Stress/Aff & Exp & Non clinical & Central & Induction & Descriptive \\
\hline 172 & Startup, \& Davey, 2001 & & & & $\mathrm{x}$ & & Anx/Mood & Exp & Non clinical & Central & Ind/Reg & Causal \\
\hline 173 & Steinberg et al., 1998 & & & & & $\mathrm{x}$ & Mood & $\operatorname{Tr}$ & Non clinical & Peripheral & Regulation & Descriptive \\
\hline 174 & Steptoe, \& Cox, 1988 & & $\mathrm{x}$ & & & & Anx/Mood & $\operatorname{Tr}$ & Non clinical & Peripheral & Regulation & Causal \\
\hline 175 & Strentz, \& Auerbach, 1988 & $\mathrm{x}$ & & & & & Anx/Stress & Exp & Non clinical & Central & Induction & Causal \\
\hline 176 & Strigo et al., 2002 & $\mathrm{x}$ & & & & & Anx & Exp & Non clinical & Central & Induction & Descriptive \\
\hline
\end{tabular}




\begin{tabular}{|c|c|c|c|c|c|c|c|c|c|c|c|}
\hline. $\mathrm{N}$ & Reference & $\begin{array}{l}\text { STAI } \\
\text { State }\end{array}$ & POMS PANAS & VAS & Other & Construct & Domain & Population & Manipulation & $\begin{array}{l}\text { Direction of the } \\
\text { Effect }\end{array}$ & Approach \\
\hline 177 & Sukegawa et al., 2008 & $\mathrm{x}$ & & & & Anx & Applied & Clinical & No manipulation & & Descriptive \\
\hline 178 & Swartzman, Edelberg, \& Kemmann, 1990 & $\mathrm{x}$ & & $\mathrm{x}$ & & Anx/Stress & Exp & Non clinical & Central & Induction & Causal \\
\hline 179 & Swendsen, 1998 & & & $\mathrm{x}$ & MAACL & Anx & Applied & Non clinical & No manipulation & & Descriptive \\
\hline 180 & Tang, \& Gibson, 2005 & & & $\mathrm{x}$ & & Anx & Exp & Non clinical & Central & Induction & Causal \\
\hline 181 & Thompson, Altmann, \& Davidson, 2004 & $\mathrm{x}$ & & & & Anx & Exp & Non clinical & Central & Induction & Causal \\
\hline 182 & Tornek et al., 2003 & $\mathrm{x}$ & $\mathrm{x}$ & & & Anx/Mood & $\operatorname{Tr}$ & Clinical & Central & Regulation & Causal \\
\hline 183 & Toskovic, 2001 & & $\mathrm{x}$ & & & Mood & $\operatorname{Tr}$ & Non clinical & Peripheral & Regulation & Causal \\
\hline 184 & Tovilovic et al., 2009 & $\mathrm{x}$ & & & & Anx & Exp & Non clinical & Central & Induction & Causal \\
\hline 185 & Tulen et al., 1993 & $\mathrm{x}$ & $\mathrm{x}$ & & & Anx/Mood & Exp & Non clinical & Central & Induction & Descriptive \\
\hline 186 & Urech et al., 2010 & $\mathrm{x}$ & & & & Anx & $\operatorname{Tr}$ & Non clinical & Peripheral & Regulation & Causal \\
\hline 187 & Vadalouca et al., 2009 & $\mathrm{x}$ & & $\mathrm{x}$ & & Anx & $\operatorname{Tr}$ & Clinical & Central & Regulation & Causal \\
\hline 188 & van der Bij et al., 2003 & $\mathrm{x}$ & & & & Anx & Exp & Non clinical & Central & Regulation & Descriptive \\
\hline 189 & Verburg et al., 1998 & & & $\mathrm{x}$ & & Anx & Exp & Clinical & Central & Induction & Causal \\
\hline 190 & Villani, Riva,\& Riva, 2007 & $\mathrm{x}$ & $\mathrm{x}$ & $\mathrm{x}$ & & Anx & $\operatorname{Tr}$ & Non clinical & Central & Regulation & Causal \\
\hline 191 & Vujanovic, \& Zvolensky, 2009 & & & & SUDS & Anx & Exp & Non clinical & Central & Induction & Descriptive \\
\hline 192 & Weisberg et al., 2001 & & $\mathrm{x}$ & & & Anx & Exp & Non clinical & Central & Induction & Descriptive \\
\hline 193 & Werner et al., 2009 & $\mathrm{x}$ & & & & Anx & Exp & Non clinical & Central & Induction & Causal \\
\hline 194 & Wilson, MacLeod, \& Mathews, 2006 & & & $\mathrm{x}$ & & Anx & Exp & Non clinical & Central & Ind/Reg & Causal \\
\hline 195 & Wolanskyj et al., 2000 & $\mathrm{x}$ & & $\mathrm{x}$ & & Anx & $\operatorname{Tr}$ & Clinical & Central & Regulation & Causal \\
\hline 196 & Yiend et al., 2008 & $\mathrm{x}$ & & & & Anx & Exp & Non clinical & Central & Regulation & Descriptive \\
\hline 197 & Youngstedt, \& Kripke, 2007 & $\mathrm{x}$ & & & & Anx & $\operatorname{Tr}$ & Non clinical & Central & Regulation & Causal \\
\hline
\end{tabular}

\section{Table caption}

Table 1: 197 studies (in alphabetical order) included in our literature review and organized as a function of the main variables (Construct; Domain; Population; Manipulation; Direction of the Effect; Approach; see section 1.3 in the main text for exact definitions). All these studies were carefully selected based on specific and strict criteria (repeated measures design, testretest interval shorter than 24 hours; see section 1.2).

\section{Abbreviations:}

Other column: EAS (Emotion Assessment Scale; Carlson et al., 1989); HAM-A (Hamilton Anxiety and Depression Scale-Anxiety; Hamilton, 1959); ARQ (Arousal Rating Questionnaire; Edwards, Burt, \& Lipp, 2010); HADS-A (Hospital Anxiety and Depression Scale-A; Zigmond \& Snaith, 1983); SUDS (Subjective Units of Distress Scale; Wolpe, 1958 \& 1990); TESI (Tension and Effort Stress Inventory; Svebak et al., 1991); BAI (Beck Anxiety Inventory; Beck, Epstein, Brown, \& Steer, 1988); MRF (Mental Readiness Form; Krane, 1994); SSSSS-S (Smith Somatic Stress Symptoms Scale-State; Smith, 1990); MSQ-R (Motivational State Questionnaire-revised form; see Rogers \& Revelle 1998); MAACL-r (Multiple Affect Adjective Check List-Revised, "Today" Form; Zuckerman \& Lubin, 1985). When no name is provided for the measurement in this column, a compound measure created ad hoc was reported in the study.

Construct column: Anx = Anxiety; Aff = Affect

Domain column: Exp = Experimental; $\operatorname{Tr}=$ Treatment

Direction of Effect Column: Ind/Reg = Induction/Regulation 

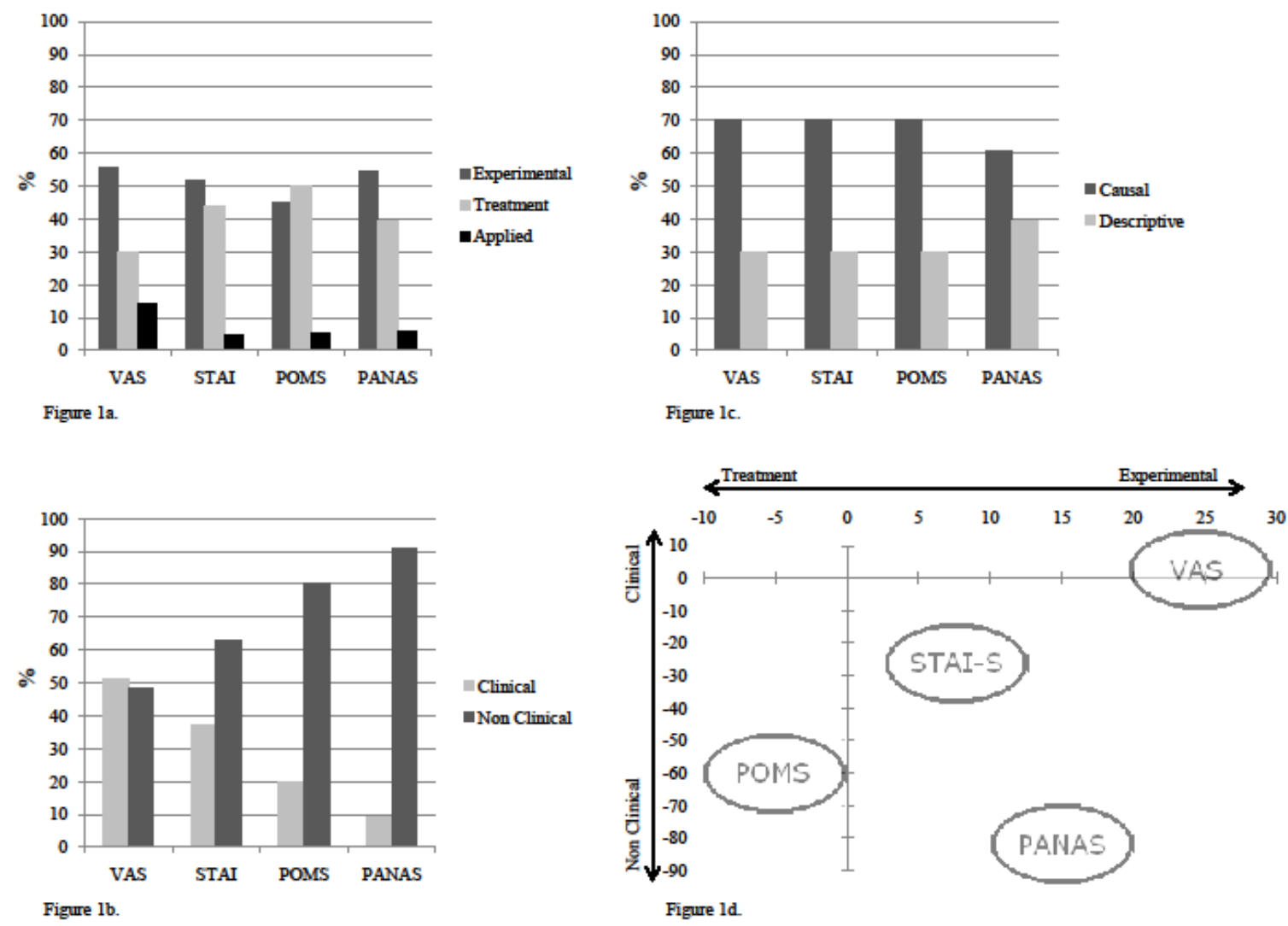

Figure 1: (a) Classification of studies (expressed in percentage) separately for each questionnaire (STAI, POMS, PANAS, and VAS) as a function of the Domain variable (Experimental, Treatment or Applied). (b) Classification of studies (expressed in percentage) as a function of the Population variable (Clinical vs. Non-clinical). (c) Classification of studies (expressed in percentage) as a function of the Approach variable (Causal vs. Descriptive). (d) A mapping of the studies using two orthogonal axes/variables (Domain vs. Population) suggests that the four instruments occupy non-overlapping mean positions, consistent with their use in different domains or contexts. For each instrument, the actual numerical value corresponds to the center of the ellipse. The horizontal axis codes the difference (in percentage) between Experimental and Treatment studies. Along this axis, a negative number indicates that the percentage of studies classified as Treatment for the given tool outnumbers the amount of studies classified as Experimental. Conversely, a positive number indicates an opposite effect (in favor of Experimental). The vertical axis codes the difference (in percentage) between Clinical and Non Clinical studies. A negative number indicates that the number of studies labeled as Non Clinical for the given tool outnumbers the amount of studies classified as Clinical. Conversely, a positive number indicates an opposite trend (in favor of Clinical). 

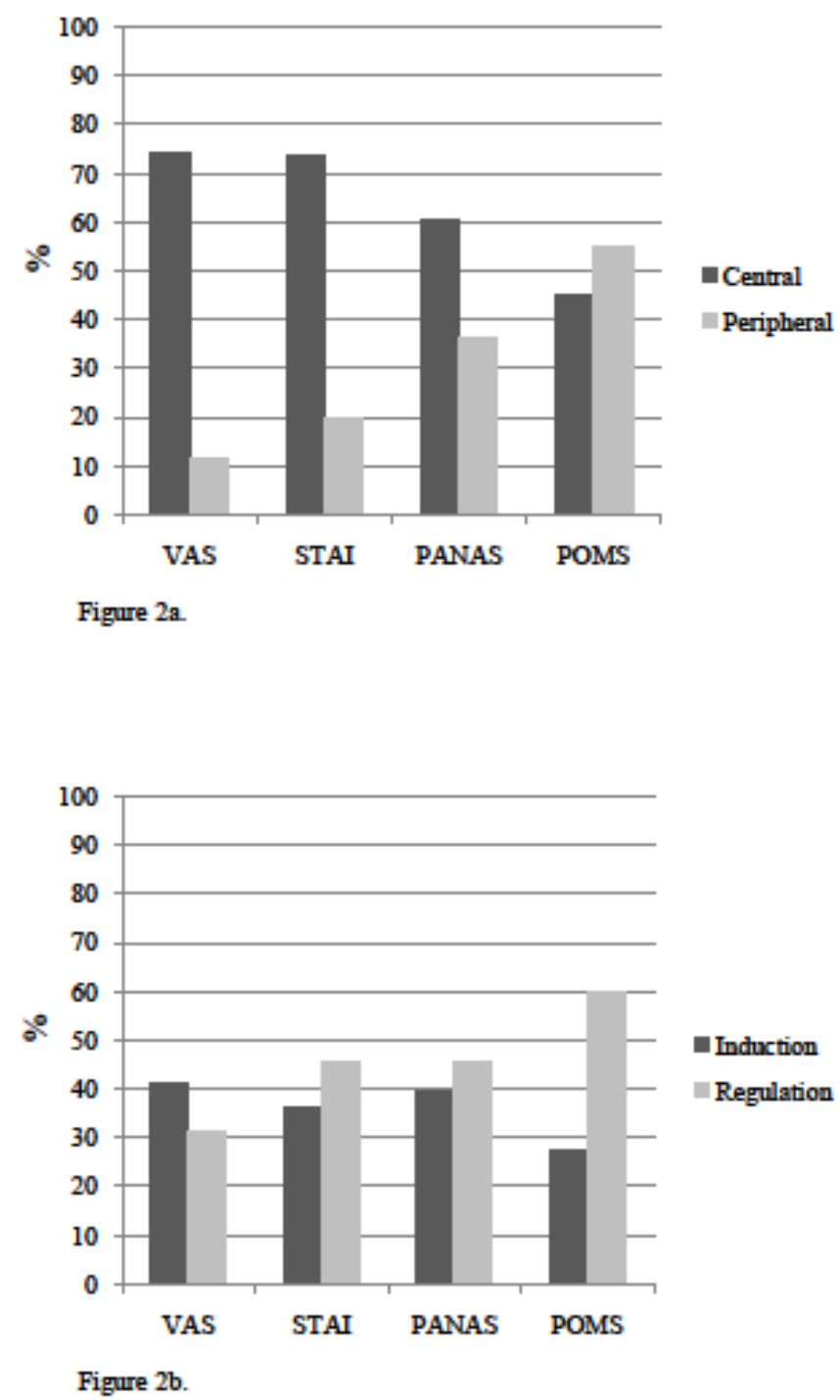

Figure 2: (a) Classification of studies (expressed in percentage) separately for each questionnaire (STAI, POMS, PANAS, and VAS) as a function of the Manipulation variable (Central vs. Peripheral). (b) Classification of studies (expressed in percentage) as a function of the Direction of the effect variable (Induction, Regulation or Combined). 


\section{Supplementary material: Table 2}

\begin{tabular}{|c|c|c|c|c|}
\hline Entry & Measures & Cronbach 's alpha & Correlations & Test-retest Reliability \\
\hline 1 & $\begin{array}{l}\text { STAI-S } \\
\text { VAS }\end{array}$ & & STAI-S VAS $r=.58$ & \\
\hline 15 & $\begin{array}{l}\text { STAI-S } \\
\text { VAS }\end{array}$ & STAI-S .55 & & $\begin{array}{l}\text { STAI-S } r=.49 \\
\text { VAS } r=.82\end{array}$ \\
\hline 16 & POMS & POMS .93 to .95 & & \\
\hline 18 & $\begin{array}{l}\text { STAI-S } \\
\text { VAR }\end{array}$ & STAI-S .92 & STAI-S VAR $r=.69$ to .73 & VAR $r=.55$ to .66 \\
\hline 30 & $\begin{array}{l}\text { STAI-S } \\
\text { PANAS }\end{array}$ & & STAI-S PANAS $r=.82$ & \\
\hline 46 & STAI-S & STAI-S .77 to .94 & & \\
\hline 59 & PANAS & PANAS .81 to .88 & & \\
\hline 73 & $\begin{array}{l}\text { STAI-S } \\
\text { VAS }\end{array}$ & STAI-S .89 & STAI-S VAS $r=.52$ to .55 & VAS $r=.59$ to .71 \\
\hline 74 & STAI-S & STAI-S .85 & & \\
\hline 90 & STAI-S & STAI-S .93 & & \\
\hline 92 & STAI-S & STAI-S .90 to .96 & & \\
\hline 97 & $\begin{array}{l}\text { STAI-S } \\
\text { PANAS }\end{array}$ & $\begin{array}{l}\text { STAI-S } .88 \text { to. } 90 \\
\text { PANAS } .79 \text { to } .82 \\
\end{array}$ & & \\
\hline 100 & $\begin{array}{l}\text { STAI-S } \\
\text { POMS-BI }\end{array}$ & & STAI-POMS-T(bipolar) $r=-.81$ & \\
\hline 102 & STAI-S & STAI-S .87 & & \\
\hline 103 & $\begin{array}{l}\text { STAI-S } \\
\text { VAS }\end{array}$ & & STAI-S VAS $r=.53$ to .68 & \\
\hline 106 & $\begin{array}{l}\text { STAI-S } \\
\text { Mood Form }\end{array}$ & $\begin{array}{l}\text { STAI-S . } 95 \text { to } .96 \\
\text { Mood Form }>.80\end{array}$ & & \\
\hline 113 & $\begin{array}{l}\text { STAI-S } \\
\text { POMS }\end{array}$ & & $\begin{array}{l}\text { STAI-POMS-T } r=.79 \\
\text { STAI-POMS TMDS } r=.78\end{array}$ & \\
\hline 131 & POMS (compound) & POMSc .96 & & POMSc $r=.74$ \\
\hline 140 & $\begin{array}{l}\text { STAI-S } \\
\text { POMS }\end{array}$ & $\begin{array}{l}\text { STAI-S } .86 \text { to } .94 \\
\text { POMS } .54 \text { to } .82\end{array}$ & & \\
\hline 145 & $\begin{array}{l}\text { STAI-S } \\
\text { VAS }\end{array}$ & & STAI-S VAS $r=.31$ to .33 & \\
\hline 146 & $\begin{array}{l}\text { STAI-S(once) } \\
\text { PANAS }\end{array}$ & $\begin{array}{l}\text { STAI-S } .94 \\
\text { PANAS } .80 \text { to } .92\end{array}$ & & \\
\hline 156 & $\begin{array}{l}\text { STAI-S (brief) } \\
\text { PANAS }\end{array}$ & STAI-S .87 & & \\
\hline 158 & POMS & POMS .70 & & (Split-half $r=.73$ to .78 ) \\
\hline 161 & STAI-S & & & STAI-S $r=.42$ \\
\hline 163 & STAI-S & STAI-S .94 & & \\
\hline 165 & VAS (compound) & VASc .86 to .95 & VASc \& Neuroticism $r=.41$ to .50 & \\
\hline 168 & $\begin{array}{l}\text { PANAS-X } \\
\text { PANAS }\end{array}$ & $\begin{array}{l}\text { PANAS-X fear } .89 \\
\text { PANAS } .79\end{array}$ & & \\
\hline 181 & $\begin{array}{l}\text { STAI-S } \\
\text { PANAS (once) }\end{array}$ & $\begin{array}{l}\text { STAI-S } .89 \text { to } .90 \\
\text { PANAS } .90\end{array}$ & & \\
\hline 184 & $\begin{array}{l}\text { STAI-S } \\
\text { PANAS (trait) }\end{array}$ & $\begin{array}{l}\text { STAI-S .90 } \\
\text { PANAS .84 }\end{array}$ & & \\
\hline 188 & $\begin{array}{l}\text { STAI-S } \\
\text { STAI-S (short) }\end{array}$ & STAI-S (short) .83 & STAI-S STAI-S (short) $r=.95$ & \\
\hline 189 & VAS & & & VAS $r=.06$ to .70 \\
\hline
\end{tabular}




\section{$\underline{\text { Table Caption }}$}

Table 2: Comparative psychometric data across the four instruments, as could be retrieved in some of the studies $(\mathrm{N}=197)$ included in our review. Entry number corresponds to an arbitrary number used to sort the studies (see Table 1).

\section{Abbreviations:}

STAI-S (State-Trait Anxiety Inventory-State Form); POMS (Profile of Mood States); POMSBI (POMS-Bipolar form); POMS-T (POMS, Tension subscale); PANAS (Positive and Negative Affect Schedule); VAS (Visual Analog Scale); VAR (Verbal Anxiety Rating)

\section{Supplementary material: Bibliographical details for studies included in Table 1}

Abdul-Latif, M. S., Putland, A. J., McCluskey, A., Meadows, D. P., \& Remington, S. A. M. (2001). Oral midazolam premedication for day case breast surgery, a randomised prospective double-blind placebo-controlled study. Anaesthesia, 56(10), 990-994. doi: 10.1111/j.13652044.2001.1974-2.x

Abercrombie, H. C., Kalin, N. H., \& Davidson, R. J. (2005). Acute cortisol elevations cause heightened arousal ratings of objectively nonarousing stimuli. Emotion, 5(3), 354-359. doi: 10.1037/1528-3542.5.3.354

Abrams, D. B., Monti, P. M., Pinto, R. P., Elder, J. P., Brown, R. A., \& Jacobus, S. I. (1987). Psychosocial stress and coping in smokers who relapse or quit. Health Psychology, 6(4), 289303. doi: 10.1037/0278-6133.6.4.289

Abrams, K., Kushner, M. G., Medina, K. L., \& Voight, A. (2002). Self-administration of alcohol before and after a public speaking challenge by individuals with social phobia. Psychology of Addictive Behaviors, 16(2), 121-128. doi: 10.1037/0893-164X.16.2.121

Amir, N., Weber, G., Beard, C., Taylor, C. T., \& Bomyea, J. (2008). The effect of a singlesession attention modification program on response to a public-speaking challenge in socially anxious individuals. Journal of Abnormal Psychology, 117(4), 860-868. doi: 10.1037/a0013445

Andrykowski, M. A., \& Redd, W. H. (1987). Longitudinal analysis of the development of anticipatory nausea. Journal of Consulting and Clinical Psychology, 55(1), 36-41. doi: 10.1037/0022-006X.55.1.36

Andrykowski, M. A., Redd, W. H., \& Hatfield, A. K. (1985). Development of anticipatory nausea: A prospective analysis. Journal of Consulting and Clinical Psychology, 53(4), 447454. doi: 10.1037/0022-006x.53.4.447

Aragon, D., Farris, C., \& Byers, J. F. (2002). The effects of harp music in vascular and thoracic surgical patients. Alternative Therapies in Health and Medicine, 8(5), 52-54, 56-60. 
Arent, S. M., Landers, D. M., Matt, K. S., \& Etnier, J. L. (2005). Dose-Response and Mechanistic Issues in the Resistance Training and Affect Relationship. Journal of Sport \& Exercise Psychology, 27(1), 92-110.

Argyropoulos, S. V., Hood, S. D., Adrover, M., Bell, C. J., Rich, A. S., Nash, J. R., et al. (2004). Tryptophan depletion reverses the therapeutic effect of selective serotonin reuptake inhibitors in social anxiety disorder. Biological Psychiatry, 56(7), 503-509. doi: 10.1016/j.biopsych.2004.07.006

Arizono, H., Morita, N., Iizuka, S., Satoh, S., \& Nakatani, Y. (2000). Reminiscence therapy using odor in alcohol-dependent patients--psychophysiological evaluation and psychological evaluation; power spectral analysis of heart rate variability. Nihon Arukoru Yakubutsu Igakkai Zasshi, 35(6), 373-387.

Arntz, A., Merckelbach, H., \& de Jong, P. J. (1993). Opioid antagonist affects behavioral effects of exposure in vivo. Journal of Consulting and Clinical Psychology, 61(5), 865-870. doi: 10.1037/0022-006X.61.5.865

Auquier, P., Macquartmoulin, G., Moatti, J. P., Blache, J. L., Novakovitch, G., Blaise, D., et al. (1995). Comparison of anxiety, pain and discomfort in 2 procedures of hematopoietic stem-cell collection: leukacytapheresis and bone-marrow harvest. Bone Marrow Transplantation, 16(4), 541-547.

Baker, R. C., \& Guttfreund, D. G. (1993). The effects of written autobiographical recollection induction procedures on mood. Journal of Clinical Psychology, 49(4), 563-568. doi: 10.1002/1097-4679(199307)49:4<563::AID-JCLP2270490414>3.0.CO;2-W

Baron, R. S., Logan, H., \& Hoppe, S. (1993). Emotional and sensory focus as mediators of dental pain among patients differing in desired and felt dental control. Health Psychology, 12(5), 381-389. doi: 10.1037/0278-6133.12.5.381

Bartholomew, J. B., Morrison, D., \& Ciccolo, J. T. (2005). Effects of Acute Exercise on Mood and Well-Being in Patients with Major Depressive Disorder. Medicine \& Science in Sports \& Exercise, 37(12), 2032-2037. doi: 10.1249/01.mss.0000178101.78322.dd

Beck, A. T., Epstein, N., Brown, G., \& Steer, R. A. (1988). An inventory for measuring clinical anxiety: Psychometric properties. Journal of Consulting and Clinical Psychology, 56, 893-897. doi: 10.1037/0022-006X.56.6.893

Benedetti, F., Maggi, G., Lopiano, L., Lanotte, M., Rainero, I., Vighetti, S., et al. (2003). Open versus hidden medical treatments: The patient's knowledge about a therapy affects the therapy outcome. Prevention \& Treatment, 6(1). doi: 10.1037/1522-3736.6.1.61a

Benotsch, E., Lutgendorf, S., Watson, D., Fick, L., \& Lang, E. (2000). Rapid anxiety assessment in medical patients: Evidence for the validity of verbal anxiety ratings. Annals of Behavioral Medicine, 22(3), 199-203. doi: 10.1007/BF02895114

Bernat, J. A., Calhoun, K. S., Adams, H. E., \& Zeichner, A. (2001). Homophobia and physical aggression toward homosexual and heterosexual individuals. Journal of Abnormal Psychology, 110(1), 179-187. doi: 10.1037/0021-843X.110.1.179 
Bixby, W. R., Spalding, T. W., \& Hatfield, B. A. (2001). Temporal dynamics and dimensional specificity of the affective response to exercise of varying intensity: Differing pathways to a common outcome. Journal of Sport \& Exercise Psychology, 23(3), 171-190.

Bodin, T., \& Martinsen, E. W. (2004). Mood and Self-Efficacy During Acute Exercise in Clinical Depression. A Randomized, Controlled Study. Journal of Sport \& Exercise Psychology, 26(4), 623-633.

Bogaerts, K., Van Eylen, L., Li, W., Bresseleers, J., Van Diest, I., De Peuter, S., et al. (2010). Distorted symptom perception in patients with medically unexplained symptoms. Journal of Abnormal Psychology, 119(1), 226-234. doi: 10.1037/a0017780

Bond, A. J., Shine, P., \& Bruce, M. (1995). Validation of visual analogue scales in anxiety. International Journal of Methods in Psychiatric Research, 5(1), 1-9.

Bowen, R., Baetz, M., Hawkes, J., \& Bowen, A. (2006). Mood variability in anxiety disorders. Journal of Affective Disorders, 91(2-3), 165-170. doi: 10.1016/j.jad.2005.12.050

Bradley, B. F., Brown, S. L., Chu, S., \& Lea, R. W. (2009). Effects of orally administered lavender essential oil on responses to anxiety-provoking film clips. Human Psychopharmacology-Clinical and Experimental, 24(4), 319-330. doi: 10.1002/hup.1016

Bringman, H., Giesecke, K., Thorne, A., \& Bringman, S. (2009). Relaxing music as premedication before surgery: a randomised controlled trial. Acta Anaesthesiologica Scandinavica, 53(6), 759-764. doi: 10.1111/j.1399-6576.2009.01969.x

Bringuier, S., Dadure, C., Raux, O., Dubois, A., Picot, M. C., \& Capdevila, X. (2009). The Perioperative Validity of the Visual Analog Anxiety Scale in Children: A Discriminant and Useful Instrument in Routine Clinical Practice to Optimize Postoperative Pain Management. Anesthesia and Analgesia, 109(3), 737-744. doi: 10.1213/ane.0b013e3181af00e4

Britt, D. M., Cohen, L. M., Frank L. Collins, J., \& Cohen, M. L. (2001). Cigarette Smoking and Chewing Gum:Response to a Laboratory-Induced Stressor. Health Psychology, 20(5), 361-368. doi: 10.1037//0278-6133.20.5.361

Bruera, E., Willey, J., Cohen, M., \& Palmer, J. L. (2008). Expressive writing in patients receiving palliative care: A feasibility study. Journal of Palliative Medicine, 11(1), 15-19. doi: 10.1089/jpm.2007.0112

Bruning, S., \& McMahon, C. (2009). The impact of infant crying on young women: A randomized controlled study. Journal of Reproductive and Infant Psychology, 27(2), 206 220. doi: $10.1080 / 02646830802350856$

Buckelew, S. P., Conway, R. C., Shutty, M. S., Lawrence, J. A., Grafing, M. R., Anderson, S. K., et al. (1992). Spontaneous coping strategies to manage acute pain and anxiety during electrodiagnostic studies. Archives of Physical Medicine and Rehabilitation, 73(6), 594-598.

Campeau, M.-P., Gaboriault, R., Drapeau, M., Van Nguyen, T., Roy, I., Fortin, B., et al. (2007). Impact of massage therapy on anxiety levels in patients undergoing radiation therapy: randomized controlled trial. Journal of the Society for Integrative Oncology, 5(4), 133-138.

Carrillo, E., Moya-Albiol, L., Gonzalez-Bono, E., Salvador, A., Ricarte, J., \& Gomez-Amor, J. (2001). Gender differences in cardiovascular and electrodermal responses to public 
speaking task: the role of anxiety and mood states. International Journal of Psychophysiology, 42(3), 253-264. doi: 10.1016/s0167-8760(01)00147-7

Carter, M. M., Hollon, S. D., Carson, R., \& Shelton, R. C. (1995). Effects of a safe person on induced distress following a biological challenge in panic disorder with agoraphobia. $J$ Journal of Abnormal Psychology, 104(1), 156-163. doi: 10.1037/0021-843X.104.1.156

Caumo, W., Broenstrub, J. C., Fialho, L., Petry, S. M. G., Brathwait, O., Bandeira, D., et al. (2000). Risk factors for postoperative anxiety in children. Acta Anaesthesiologica Scandinavica, 44(7), 782-789. doi: 10.1034/j.1399-6576.2000.440703.x

Chan, Y. M., Lee, P. W. H., Ng, T. Y., Ngan, H. Y. S., \& Wong, L. C. (2003). The use of music to reduce anxiety for patients undergoing colposcopy: a randomized trial. Gynecologic Oncology, 91(1), 213-217. doi: 10.1016/s0090-8258(03)00412-8

Chua, P., Krams, M., Toni, I., Passingham, R., \& Dolan, R. (1999). A functional anatomy of anticipatory anxiety. Neuroimage, 9(6), 563-571. doi: 10.1006/nimg.1999.0407

Cinciripini, P. M., Robinson, J. D., Carter, B. L., Lam, C., Wu, X., de Moor, C. A., et al. (2006). The effects of smoking deprivation and nicotine administration on emotional reactivity. Nicotine \& Tobacco Research, 8(3), 379-392 doi: 10.1080/14622200600670272

Clark, C. P., \& Golshan, S. (2008). Antidepressant response to partial sleep deprivation in unipolar depression is not related to state anxiety. Depression and Anxiety, 25(7), E12-14. doi: 10.1002/da.20424

Cools, R., Calder, A. J., Lawrence, A. D., Clark, L., Bullmore, E., \& Robbins, T. W. (2005). Individual differences in threat sensitivity predict serotonergic modulation of amygdala response to fearful faces. Psychopharmacology, 180(4), 670-679. doi: 10.1007/s00213-005$2215-5$

Corchs, F., Nutt, D. J., Hood, S., \& Bernik, M. (2009). Serotonin and Sensitivity to TraumaRelated Exposure in Selective Serotonin Reuptake Inhibitors-Recovered Posttraumatic Stress Disorder. Biological Psychiatry, 66(1), 17-24. doi: 10.1016/j.biopsych.2009.01.031

Cruise, C. J., Chung, F., Yogendran, S., \& Little, D. (1997). Music increases satisfaction in elderly outpatients undergoing cataract surgery. Canadian Journal of Anaesthesia-Journal Canadien D Anesthesie, 44(1), 43-48. doi: 10.1007/BF03014323

Daley, A. J., \& Maynard, I. W. (2003). Preferred exercise mode and affective responses in physically active adults. Psychology of Sport and Exercise, 4(4), 347-356. doi: 10.1016/S1469-0292(02)00018-3

de-Paris, F., Sant'Anna, M. K., Vianna, M. R. M., Barichello, T., Busnello, J. V., Kapczinski, F., et al. (2003). Effects of Gabapentin on Anxiety Induced by Simulated Public Speaking. Journal of Psychopharmacology, 17(2), 184-188. doi: 10.1177/0269881103017002006

Diego, M. A., Jones, N. A., Field, T., Hernandez-Reif, M., Schanberg, S., Kuhn, C., et al. (1998). Aromatherapy positively affects mood, EEG patterns of alertness and math computations. International Journal of Neuroscience, 96(3-4), 217-224. doi: $10.3109 / 00207459808986469$ 
Donoyama, N., Munakata, T., \& Shibasaki, M. (2010). Effects of Anma therapy (traditional Japanese massage) on body and mind. Journal of Bodywork and Movement Therapies, 14(1), 55-64. doi: 10.1016/j.jbmt.2008.06.007

Duka, T., Goerke, D., Dorow, R., Holler, L., \& Fichte, K. (1988). Human studies on the benzodiazepine receptor antagonist Beta-Carboline ZK-93-426: Antagonism of Lormetazepam psychotropic effects. Psychopharmacology, 95(4), 463-471. doi: 10.1007/BF00172956

Durkin, S. J., \& Paxton, S. J. (2002). Predictors of vulnerability to reduced body image satisfaction and psychological wellbeing in response to exposure to idealized female media images in adolescent girls. Journal of Psychosomatic Research, 53(5), 995-1005. doi: 10.1016/S0022-3999(02)00489-0

Edwards, M. S., Burt, J. S., \& Lipp, O. V. (2010). Selective attention for masked and unmasked threatening words in anxiety: Effects of trait anxiety, state anxiety and awareness. Behaviour Research and Therapy, 48(3), 210-218. doi: 10.1016/j.brat.2009.11.003

Ekwall, A., Gerdtz, M., \& Manias, E. (2009). Anxiety as a factor influencing satisfaction with emergency department care: Perspectives of accompanying persons. Journal of Clinical Nursing, 18(24), 3489-3497. doi: 10.1111/j.1365-2702.2009.02873.x

Erb, T., Sluga, M., Hampl, K. F., Ummenhofer, W., \& Schneider, M. C. (1998). Preoperative anxiolysis with minimal sedation in elderly patients: bromazepam or clorazepatedipotassium? Acta Anaesthesiologica Scandinavica, 42(1), 97-101. doi: 10.1111/j.13996576.1998.tb05087.x

Eubank, M., Collins, D., \& Smith, N. (2002). Anxiety and ambiguity: It's all open to interpretation. Journal of Sport \& Exercise Psychology, 24(3), 239-253.

Ferrer-Garcia, M., \& Gutiérrez Maldonado, J. (2005). Assessment of emotional reactivity produced by exposure to virtual environments in patients with eating disorders. Annual Review of CyberTherapy and Telemedicine, 3, 123-128.

Field, T., Ironson, G., Scafidi, F., Nawrocki, T., Goncalves, A., \& Burman, I. (1996). Massage therapy reduces anxiety and enhances EEG pattern of alertness and math computations. International Journal of Neuroscience, 86(3-4), 197-205. doi: $10.3109 / 00207459608986710$

Focht, B. C., \& Koltyn, K. F. (1999). Influence of resistance exercise of different intensities on state anxiety and blood pressure. Medicine and Science in Sports and Exercise, 31(3), 456-463.

Fox, E., Russo, R., Bowles, R., \& Dutton, K. (2001). Do threatening stimuli draw or hold visual attention in subclinical anxiety? Journal of Experimental Psychology: General, 130(4), 681-700. doi: 10.1037//0096-3445.130.4.681

Fumoto, M., Sato-Suzuki, I., Seki, Y., Mohri, Y., \& Arita, H. (2004). Appearance of highfrequency alpha band with disappearance of low-frequency alpha band in EEG is produced during voluntary abdominal breathing in an eyes-closed condition. Neuroscience Research, 50(3), 307-317. doi: 10.1016/j.neures.2004.08.005 
Garvin, A. W., \& Damson, C. (2008). The Effects of Idealized Fitness Images on Anxiety, Depression and Global Mood States in College Age Males and Females. Journal of Health Psychology, 13(3), 433-437. doi: 10.1177/1359105307088146

Gaudreau, P., Blondin, J. P., \& Lapierre, A. M. (2002). Athletes' coping during a competition: relationship of coping strategies with positive affect, negative affect, and performance-goal discrepancy. Psychology of Sport and Exercise, 3(2), 125-150. doi: 10.1016/S1469-0292(01)00015-2

Geeraerts, B., Vandenberghe, J., Van Oudenhove, L., Gregory, L. J., Aziz, Q., Dupont, P., et al. (2005). Influence of experimentally induced anxiety on gastric sensorimotor function in humans. Gastroenterology, 129(5), 1437-1444. doi: 10.1053/j.gastro.2005.08.020

Gejervall, A. L., Stener-Victorin, E., Moller, A., Janson, P. O., Werner, C., \& Bergh, C. (2005). Electro-acupuncture versus conventional analgesia: a comparison of pain levels during oocyte aspiration and patients' experiences of well-being after surgery. Human Reproduction, 20(3), 728-735. doi: 10.1093/humrep/deh665

Gilbert, G. S., Parker, J. C., \& Claiborn, C. D. (1978). Differential mood changes in alcoholics as a function of anxiety management strategies. Journal of Clinical Psychology, 34(1), 229-232. doi: 10.1002/1097-4679(197801)34:1<229::AIDJCLP2270340147>3.0.CO;2-Z

Goldin, P. R., Manber-Ball, T., Werner, K., Heimberg, R., \& Gross, J. J. (2009). Neural Mechanisms of Cognitive Reappraisal of Negative Self-Beliefs in Social Anxiety Disorder. Biological Psychiatry, 66(12), 1091-1099. doi: 10.1016/j.biopsych.2009.07.014

Grasing, K., Sturgill, M. G., Rosen, R. C., Trout, J. R., Thomas, T. J., Kulkarni, G. D., et al. (1996). Effects of yohimbine on autonomic measures are determined by individual values for area under the concentration-time curve. Journal of Clinical Pharmacology, 36(9), 814-822.

Grassi, A., Gaggioli, A., \& Riva, G. (2009). The Green Valley: The Use of Mobile Narratives for Reducing Stress in Commuters. CyberPsychology \& Behavior, 12(2), 155-161. doi: $10.1089 / \mathrm{cpb} .2008 .0156$

Grillon, C., Cordova, J., Levine, L., \& Morgan, I. I. I. C. (2003). Anxiolytic effects of a novel group II metabotropic glutamate receptor agonist (LY354740) in the fear-potentiated startle paradigm in humans. Psychopharmacology, 168(4), 446-454 doi: 10.1007/s00213-003-14448

Gutierrez-Maldonado, J., Ferrer-Garcia, M., Caqueo-Urizar, A., \& Letosa-Porta, A. (2006). Assessment of emotional reactivity produced by exposure to virtual environments in patients with eating disorders. Cyberpsychology \& Behavior, 9(5), 507-513. doi: $10.1089 / \mathrm{cpb} .2006 .9 .507$

Hale, B. S., \& Raglin, J. S. (2002). State anxiety responses to acute resistance training and step aerobic exercise across 8-weeks of training. Journal of Sports Medicine and Physical Fitness, 42(1), 108-112.

Hatayama, T., Kitamura, S., Tamura, C., Nagano, M., \& Ohnuki, K. (2008). The facial massage reduced anxiety and negative mood status, and increased sympathetic nervous activity. Biomedical Research, 29(6), 317-320 doi: 10.2220/biomedres.29.317. 
Hayasaka, S., Nakamura, Y., Kajii, E., Ide, M., Shibata, Y., Noda, T., et al. (2008). Effects of charcoal kiln saunas (Jjimjilbang) on psychological states. Complementary Therapies in Clinical Practice, 14(2), 143-148 doi: 10.1016/j.ctcp.2007.12.004.

Hayasaka, S., Tsutsumi, A., Noda, T., Murata, C., \& Ojima, T. (2009). Effects of stone spa (Ganban-yoku) on psychological states. Complementary Therapies in Clinical Practice, 15(3), 129-132 doi: 10.1016/j.ctcp.2009.06.007.

Head, A., Kendall, M. J., Ferner, R., \& Eagles, C. (1996). Acute effects of beta blockade and exercise on mood and anxiety. British Journal of Sports Medicine, 30(3), 238-242 doi: 10.1136/bjsm.30.3.238.

Heikkilä, J., Paunonen, M., Virtanen, V., \& Laippala, P. (1998). Fear of patients related to coronary arteriography. Journal of Advanced Nursing, 28(1), 54-62 doi: 10.1046/j.13652648.1998.00764.x.

Hofer, C. K., Zollinger, A., Buchi, S., Klaghofer, R., Serafino, D., Buhlmann, S., et al. (2003). Patient well-being after general anaesthesia: a prospective, randomized, controlled multi-centre trial comparing intravenous and inhalation anaesthesia. British Journal of Anaesthesia, 91(5), 631-637. doi: 10.1093/bja/aeg243

Holmes, E. A., Lang, T. J., \& Shah, D. M. (2009). Developing interpretation bias modification as a "cognitive vaccine" for depressed mood: Imagining positive events makes you feel better than thinking about them verbally. Journal of Abnormal Psychology, 118(1), 76-88. doi: 10.1037/a0012590

Holmes, E. A., \& Mathews, A. (2005). Mental Imagery and Emotion: A Special Relationship? Emotion, 5(4), 489-497. doi: 10.1037/1528-3542.5.4.489

Holmes, E. A., Mathews, A., Mackintosh, B., \& Dalgleish, T. (2008). The causal effect of mental imagery on emotion assessed using picture-word cues. Emotion, 8(3), 395-409. doi: 10.1037/1528-3542.8.3.395

Hood, S. D., Hince, D. A., Davies, S. J. C., Argyropoulos, S., Robinson, H., Potokar, J., et al. (2010). Effects of acute tryptophan depletion in serotonin reuptake inhibitor-remitted patients with generalized anxiety disorder. Psychopharmacology, 208(2), 223-232. doi: $10.1007 / \mathrm{s} 00213-009-1722-1$

Hood, S. D., Hince, D. A., Robinson, H., Cirillo, M., Christmas, D., \& Kaye, J. M. (2006). Serotonin regulation of the human stress response. Psychoneuroendocrinology, 31(9), 10871097. doi: 10.1016/j.psyneuen.2006.07.001

Hopko, D. R., Hunt, M. K., \& Armento, M. E. A. (2005). Attentional task aptitude and performance anxiety. International Journal of Stress Management, 12(4), 389-408. doi: 10.1037/1072-5245.12.4.389

Hughes, A. A., \& Kendall, P. C. (2008). Effect of a positive emotional state on interpretation bias for threat in children with anxiety disorders. Emotion, 8(3), 414-418. doi: 10.1037/15283542.8.3.414

Ihme, J. M., \& Mitte, K. (2009). Measuring State Disgust Evaluation of a German State Disgust Scale. European Journal of Psychological Assessment, 25(3), 150-156. doi: 10.1027/1015-5759.25.3.150 
Iizawa, A., Oshima, T., Kasuya, Y., \& Dohi, S. (2004). Oral tandospirone and clonidine provide similar relief of preoperative anxiety. Canadian Journal of Anaesthesia-Journal Canadien D Anesthesie, 51(7), 668-671. doi: 10.1007/BF03018423

Imura, M., Misao, H., \& Ushijima, H. (2006). The Psychological Effects of AromatherapyMassage in Healthy Postpartum Mothers. Journal of Midwifery \& Women's Health, 51(2), e21-e27. doi: 10.1016/j.jmwh.2005.08.009

Jacobsen, P. B., Bovbjerg, D. H., Schwartz, M. D., Hudis, C. A., Gilewski, T. A., \& Norton, L. (1995). Conditioned emotional distress in women receiving chemotherapy for breast cancer. Journal of Consulting and Clinical Psychology, 63(1), 108-114. doi: 10.1037/0022006X.63.1.108

Järvekülg, A. (2005). The influence of environmental conditions on the benefits of aerobic gymnastics. Kinesiology, 37(1), 84-91.

Järvekülg, A., Neissaar, I., \& Viru, A. (2001). Acute anxiolytic and the mood balancing effects of aerobics in relation to environmental conditions. Kinesiology, 33(1), 20-26.

Jerabek, I., Boulenger, J. P., Lavallee, Y. J., \& Jolicoeur, F. B. (1998). Psychological predictors of CCK4-induced panic-like symptoms. Human Psychopharmacology-Clinical and Experimental, 13(1), 35-42. doi: 10.1002/(SICI)1099-1077(199801)13:1<35::AIDHUP948>3.0.CO;2-G

Johansson, M., Hassmén, P., \& Jouper, J. (2008). Acute effects of qigong exercise on mood and anxiety. International Journal of Stress Management, 15(2), 199-207. doi: 10.1037/10725245.15.2.199

Juliano, L. M., Brandon, T. H., \& Moffitt, L. (2002). Effects of Nicotine Dose, Instructional Set, and Outcome Expectancies on the Subjective Effects of Smoking in the Presence of a Stressor. J Abnormal Psichol, 111(1), 88-97. doi: 10.1037/0021-843X.111.1.88

Kagaya, A., Kugaya, A., Takebayashi, M., Fukue-Saeki, M., Saeki, T., Yamawaki, S., et al. (2001). Plasma concentrations of interleukin-1 beta, interleukin-6, soluble interleukin-2 receptor and tumor necrosis factor alpha of depressed patients in Japan. Neuropsychobiology, 43(2), 59-62. doi: 10.1159/000054867

Kassel, J. D., \& Unrod, M. (2000). Smoking, anxiety, and attention: Support for the role of nicotine in attentionally mediated anxiolysis. Journal of Abnormal Psychology, 109(1), 161166. doi: 10.1037/0021-843X.109.1.161

Kennedy, M. M., \& Newton, M. (1997). Effect of exercise intensity on mood in step aerobics. Journal of Sports Medicine and Physical Fitness, 37(3), 200-204.

Kerr, J. H., Wilson, G. V., Bowling, A., \& Sheahan, J. P. (2005). Game outcome and elite Japanese women's field hockey player's experience of emotions and stress. Psychology of Sport and Exercise, 6(2), 251-263. doi: 10.1016/j.psychsport.2003.11.002

Kimberger, O., Illievich, U., \& Lenhardt, R. (2007). The effect of skin surface warming on pre-operative anxiety in neurosurgery patients. Anaesthesia, 62(2), 140-145. doi: 10.1111/j.1365-2044.2007.04934.x 
Koukounas, E., \& McCabe, M. P. (2001). Sexual and emotional variables influencing sexual response to erotica: A psychophysiological investigation. Archives of Sexual Behavior, 30(4), 393-408. doi: 10.1023/A:1010261315767

Kraemer, J. M., \& Marquez, D. X. (2009). Psychosocial correlates and outcomes of yoga or walking among older adults. The Journal of Psychology, 143(4), 390-404. doi: 10.3200/JRLP.143.4.390-404

Kreutz, G., Bongard, S., Rohrmann, S., Hodapp, V., \& Grebe, D. (2004). Effects of choir singing or listening on secretory immunoglobulin A, cortisol, and emotional state. Journal of Behavioral Medicine, 27(6), 623-635. doi: 10.1007/s10865-004-0006-9

Krueger, T. H. C., Haake, P., Heller, H. W., Exton, M. S., Hauffa, B. P., \& Schedlowski, M. (2005). The Dental Anxiety Scale and effects of dental fear on salivary cortisol. Perceptual and Motor Skills, 100(1), 109-117. doi: 10.2466/pms.100.1.109-117

Laidlaw, T. M., Naito, A., Dwivedi, P., Hansi, N. K., Henderson, D. C., \& Gruzelier, J. H. (2006). The Influence of $10 \mathrm{~min}$ of the Johrei healing method on laboratory stress. Complementary Therapies in Medicine, 14(2), 127-132. doi: 10.1016/j.ctim.2005.07.001

Law, A., Logan, H., \& Baron, R. S. (1994). Desire for control, felt control, and stress inoculation training during dental treatment. Journal of Personality and Social Psychology, 926-936. doi: 10.1037/0022-3514.67.5.926

LeBlanc, V. R., Regehr, C., Jelley, R. B., \& Barath, I. (2008). The relationship between coping styles, performance, and responses to stressful scenarios in police recruits. International Journal of Stress Management, 15(1), 76-93. doi: 10.1037/1072-5245.15.1.76

Lepage, C., Drolet, P., Girard, M., Grenier, Y., \& DeGagne, R. (2001). Music decreases sedative requirements during spinal anesthesia. Anesthesia and Analgesia, 93(4), 912-916.

Li, X. Y., Wu, X. Y., Fu, C., Shen, X. F., Wu, Y. H., \& Wang, T. (2000). Effects of acute mild and moderate hypoxia on human mood state. Space Medicine and Medical Engeneering (Beijing), 13(1), 1-5.

Liotti, M., Mayberg, H. S., Brannan, S. K., McGinnis, S., Jerabek, P., \& Fox, P. T. (2000). Differential limbic-cortical correlates of sadness and anxiety in healthy subjects: implications for affective disorders. Biological Psychiatry, 48(1), 30-42. doi: 10.1016/S00063223(00)00874-X

Litvin, E. B., \& Brandon, T. H. (2010). Testing the Influence of External and Internal Cues on Smoking Motivation Using a Community Sample. Experimental and Clinical Psychopharmacology, 18(1), 61-70. doi: 10.1037/a0017414

Liu, Y. F., Mimura, K., Wang, L. X., \& Ikuta, K. (2005). Psychological and physiological effects of 24-style Taijiquan. Neuropsychobiology, 52(4), 212-218. doi: 10.1159/000089485

Lu, K., Gray, M. A., Oliver, C., Liley, D. T., Harrison, B. J., Bartholomeusz, C. F., et al. (2004). The acute effects of L-theanine in comparison with alprazolam on anticipatory anxiety in humans. Human Psychopharmacology-Clinical and Experimental, 19(7), 457-465. doi: 10.1002/hup.611 
Lucas, A., Holtmann, G., Gerken, G., Pietsch, A., Braun-Lang, U., Gilani, K., et al. (2006). Visceral pain and public speaking stress: Neuroendocrine and immune cell responses in healthy subjects. Brain Behavior and Immunity, 20(1), 49-56. doi: 10.1016/j.bbi.2005.03.009

Man, A. K. Y., Yap, J. C. M., Kwan, S. Y., Suen, K. L., Yip, H. S., \& Chen, P. P. (2003). The effect of intra-operative video on patient anxiety. Anaesthesia, 58(1), 64-68. doi: 10.1046/j.1365-2044.2003.02788_4.x

Martelli, M. F., Auerbach, S. M., Alexander, J., \& Mercuri, L. G. (1987). Stress management in the health care setting: Matching interventions with patient coping styles. Journal of Consulting and Clinical Psychology, 55(2), 201-207. doi: 10.1037/0022-006X.55.2.201

Masdrakis, V. G., Markianos, M., Vaidakis, N., Papakostas, Y. G., \& Oulis, P. (2009). Caffeine challenge and breath-holding duration in patients with panic disorder. Progress in Neuro-Psychopharmacology and Biological Psychiatry, 33(1), 41-44. doi: 10.1016/j.pnpbp.2008.10.002

Masters, K. S., Lacaille, R. A., \& Shearer, D. S. (2003). The acute affective response of Type A Behaviour Pattern individuals to competitive and noncompetitive exercise. Canadian Journal of Behavioural Science/Revue canadienne des Sciences du comportement, 35(1), 2534. doi: $10.1037 / \mathrm{h} 0087183$

Mathews, A., \& Mackintosh, B. (2000). Induced emotional interpretation bias and anxiety. Journal of Abnormal Psychology, 109(4), 602-615. doi: 10.1037/0021-843X.109.4.602

McDermut, W., \& Haaga, D. A. F. (1998). Effect of stage of change on cue reactivity in continuing smokers. Experimental and Clinical Psychopharmacology, 6(3), 316-324. doi: 10.1037/1064-1297.6.3.316

Meinberg, R. A., \& Yager, G. G. (1985). Effects of a workshop fee on women's stress management skills and evaluations. Journal of Counseling Psychology, 32(4), 626-629. doi: $10.1037 / 0022-0167.32 .4 .626$

Mendonca-de-Souza, A. C. F., Souza, G. G. L., Vieira, A., Fischer, N. L., Souza, W. F., Rumjanek, V. M., et al. (2007). Negative affect as a predisposing factor for cortisol release after an acute stressor: the impact of unpleasant priming. Stress: The International Journal on the Biology of Stress, 10(4), 362-367. doi: 10.1080/10253890701379999

Mercer, A., Warson, E., \& Zhao, J. (2010). Visual journaling: An intervention to influence stress, anxiety and affect levels in medical students. Arts in Psychotherapy, 37(2), 143-148. doi: 10.1016/j.aip.2009.12.003

Merckaert, I., Libert, Y., Bron, D., Jaivenois, M.-F., Martiat, P., Slachmuylder, J.-L., et al. (2009). Impact of life-threatening risk information on the evolution of patients' anxiety and risk recall: The specific context of informed consent for experimental stem cell transplant. Patient Education and Counseling, 75(2), 192-198. doi: 10.1016/j.pec.2008.09.013

Miller, B. M., Bartholomew, J. B., \& Springer, B. A. (2005). Post-exercise affect: The effect of mode preference. Journal of Applied Sport Psychology, 17(4), 263-272. doi: $10.1080 / 10413200500313503$

Miller, T. P., Taylor, J. L., \& Tinklenberg, J. R. (1988). A comparison of assessment techniques measuring the effects of Methylphenidate, Secobarbital, Diazepam and 
Diphenhydramine in abstinent alcoholics. Neuropsychobiology, 19(2), 90-96. doi: $10.1159 / 000118441$

Mitchell, L. A., MacDonald, R. A. R., \& Knussen, C. (2008). An investigation of the effects of music and art on pain perception. Psychology of Aesthetics, Creativity, and the Arts, 2(3), 162-170. doi: 10.1037/1931-3896.2.3.162

Modena, M. G., Corghi, F., Fantini, G., \& Mattioli, G. (1989). Echocardiographic monitoring of mental stress test in ischemic heart disease. Clinical Cardiology, 12(1), 21-24. doi: $10.1002 /$ clc. 4960120104

Moser, J. S., Hajcak, G., \& Simons, R. F. (2005). The effects of fear on performance monitoring and attentional allocation. Psychophysiology, 42(3), 261-268. doi: 10.1111/j.1469-8986.2005.00290.x

Munafo, M. R., Hayward, G., \& Harmer, C. (2006). Selective processing of social threat cues following acute tryptophan depletion. Journal of Psychopharmacology, 20(1), 33-39. doi: $10.1177 / 0269881105056667$

Muzzarelli, L., Force, M., \& Sebold, M. (2006). Aromatherapy and reducing preprocedural anxiety - A controlled prospective study. Gastroenterology Nursing, 29(6), 466-471.

Nainis, N., Paice, J. A., Ratner, J., Wirth, J. H., Lai, J., \& Shott, S. (2006). Relieving symptoms in cancer: Innovative use of art therapy. Journal of Pain and Symptom Management, 31(2), 162-169. doi: 10.1016/j.jpainsymman.2005.07.006

Nakane, H., Asami, O., Yamada, Y., \& Ohira, H. (2002). Effect of negative air ions on computer operation, anxiety and salivary chromogranin A-like immunoreactivity. International Journal of Psychophysiology, 46(1), 85-89. doi: 10.1016/S01678760(02)00067-3

Neissaar, I., Kikas, M., Järvekülg, A., Viru, A., \& Viru, M. (2002). Acute anxiolytic and mood balancing effects of aerobic gymnastics: Relationship to age, personal traits and initial anxiety levels. Kinesiology, 34(1), 86-93.

Noto, Y., Sato, T., Kudo, M., Kurata, K., \& Hirota, K. (2005). The relationship between salivary biomarkers and State-Trait Anxiety Inventory score under mental arithmetic stress: A pilot study. Anesthesia and Analgesia, 101(6), 1873-1876. doi: 10.1213/01.ane.0000184196.60838.8d

O'Brien, A., Terry, D. J., \& Jimmieson, N. L. (2008). Negative affectivity and responses to work stressors: An experimental study. Anxiety, Stress \& Coping: An International Journal, 21(1), 55 - 83. doi: 10.1080/10615800701529504

O'Halloran, P. D., Murphy, G. C., \& Webster, K. E. (2004). Mood during a 60-minute treadmill run: timing and type of mood change. International Journal of Sport Psychology, 35(4), 309-327.

Okawa, K., Ichinohe, T., \& Kaneko, Y. (2005). Anxiety may enhance pain during dental treatment. Bull Tokyo Dent Coll, 46(3), 51-58. doi: 10.2209/tdcpublication.46.51

Oldman, M., Moore, D., \& Collins, S. (2004). Drug patient information leaflets in anaesthesia: effect on anxiety and patient satisfaction. British Journal of Anaesthesia, 92(6), 854-858. doi: 10.1093/bja/aeh162 
Oliveira, T., Gouveia, M. J., \& Oliveira, R. F. (2009). Testosterone responsiveness to winning and losing experiences in female soccer players. Psychoneuroendocrinology, 34(7), 1056-1064. doi: 10.1016/j.psyneuen.2009.02.006

Park, I. H., Kim, J.-J., Ku, J., Jang, H. J., Park, S.-H., Kim, C.-H., et al. (2009). Characteristics of social anxiety from virtual interpersonal interactions in patients with schizophrenia. Psychiatry: interpersonal and biological processes, 72(1), 79-93. doi: 10.1521/psyc.2009.72.1.79

Parr, C. J., \& Cartwright-Hatton, S. (2009). Social anxiety in adolescents: the effect of video feedback on anxiety and the self-evaluation of performance. Clinical Psychology \& Psychotherapy, 16(1), 46-54. doi: 10.1002/cpp.599

Perry, F., Parker, R. K., White, P. F., \& Clifford, P. A. (1994). Role of psychological factors in postoperative pain control and recovery with patient-controlled analgesia. Clinical Journal of Pain, 10(1), 57-63.

Perry, S. W., Jacobsberg, L. B., Fishman, B., Weiler, P. H., Gold, J. W. M., \& Frances, A. J. (1990). Psychological responses to serological testing for HIV. Aids, 4(2), 145-152.

Petruzzello, S. J., Snook, E. M., Gliottoni, R. C., \& Motl, R. W. (2009). Anxiety and mood changes associated with acute cycling in persons with multiple sclerosis. Anxiety, Stress \& Coping: An International Journal, 22(3), 297 - 307. doi: 10.1080/10615800802441245

Philippot, P., Baeyens, C., \& Douilliez, C. (2006). Specifying emotional information: Regulation of emotional intensity via executive processes. Emotion, 6(4), 560-571. doi: 10.1037/1528-3542.6.4.560

Phillips, J. P., \& Giancola, P. R. (2008). Experimentally induced anxiety attenuates alcoholrelated aggression in men. Experimental and Clinical Psychopharmacology, 16(1), 43-56. doi: 10.1037/1064-1297.16.1.43

Polman, R., Nicholls, A. R., Cohen, J., \& Borkoles, E. (2007). The influence of game location and outcome on behaviour and mood states among professional rugby league players. Journal of Sports Sciences, 25(13), 1491-1500. doi: 10.1080/02640410601175436

Poma, S. Z., Milleri, S., Squassante, L., Nucci, G., Bani, M., Perini, G. I., et al. (2005). Characterization of a $7 \%$ carbon dioxide (CO2) inhalation paradigm to evoke anxiety symptoms in healthy subjects. $J$ Psychopharmacol, 19(5), 494-503. doi: $10.1177 / 0269881105056533$

Prabhu, M., Wang, L. F., Tait, A. R., \& Bullough, A. S. (2009). A randomized controlled study of whether the partner's presence in the operating room during neuraxial anesthesia for cesarean delivery reduces patient anxiety. International Journal of Obstetric Anesthesia, 18(4), 362-367. doi: 10.1016/j.ijoa.2009.04.003

Rabe, S., Beauducel, A., Zöllner, T., Karl, A., \& Maercker, A. (2006). Regional brain electrical activity in posttraumatic stress disorder after motor vehicle accident. Journal of Abnormal Psychology, 115(4), 687-698. doi: 10.1037/0021-843X.115.4.687

Raes, F., Hermans, D., de Decker, A., Eelen, P., \& Williams, J. M. G. (2003). Autobiographical memory specificity and affect regulation: An experimental approach. Emotion, 3(2), 201-206. doi: 10.1037/1528-3542.3.2.201 
Raglin, J. S., \& Wilson, M. (1996). State anxiety following 20 minutes of bicycle ergometer exercise at selected intensities. International Journal of Sports Medicine, 17(6), 467-471. doi: $10.1055 / \mathrm{s}-2007-972880$

Rausch, S. M., Gramling, S. E., \& Auerbach, S. M. (2006). Effects of a single session of large-group meditation and progressive muscle relaxation training on stress reduction, reactivity, and recovery. International Journal of Stress Management, 13(3), 273-290. doi: 10.1037/1072-5245.13.3.273

Redd, W. H., Jacobsen, P. B., Die-Trill, M., Dermatis, H., McEvoy, M., \& Holland, J. C. (1987). Cognitive/attentional distraction in the control of conditioned nausea in pediatric cancer patients receiving chemotherapy. Journal of Consulting and Clinical Psychology, 55(3), 391-395. doi: 10.1037/0022-006X.55.3.391

Reinecke, A., Rinck, M., \& Becker, E. S. (2006). Spiders Crawl Easily Through the Bottleneck: Visual Working Memory for Negative Stimuli. Emotion, 6(3), 438-449. doi: 10.1037/1528-3542.6.3.438

Rejeski, W. J., Gauvin, L., Hobson, M. L., \& Norris, J. L. (1995). Effects of baseline responses, in-task feelings, and duration of activity on exercise-induced feeling states in women. Health Psychology, 14(4), 350-359. doi: 10.1037/0278-6133.14.4.350

Ren, Z. Y., Shi, J., Epstein, D. H., Wang, J., \& Lu, L. (2009). Abnormal pain response in pain-sensitive opiate addicts after prolonged abstinence predicts increased drug craving. Psychopharmacology, 204(3), 423-429. doi: 10.1007/s00213-009-1472-0

Rinck, M., Reinecke, A., Ellwart, T., Heuer, K., \& Becker, E. S. (2005). Speeded detection and increased distraction in fear of spiders: Evidence from eye movements. Journal of Abnormal Psychology, 114(2), 235-248. doi: 10.1037/0021-843X.114.2.235

Robb, S. L. (2000). Music assisted progressive muscle relaxation, progressive muscle relaxation, music listening, and silence: A comparison of relaxation techniques. Journal of Music Therapy, 37(1), 2-21.

Rodebaugh, T. L., Jakatdar, T. A., Rosenberg, A., \& Heimberg, R. G. (2009). Thinking about social situations: The moderated effects of imposing structure. Behaviour Research and Therapy, 47(2), 158-163. doi: 10.1016/j.brat.2008.10.019

Rogers, G. M., \& Revelle, W. (1998). Personality, mood, and the evaluation of affective and neutral word pairs. Journal of Personality and Social Psychology, 74(6), 1592-1605. doi: 10.1037/0022-3514.74.6.1592

Rosa, D. A., De Mello, M. T., Negrao, A. B., \& De Souza-Formigoni, M. L. O. (2004). Mood changes after maximal exercise testing in subjects with symptoms of exercise dependence. Perceptual and Motor Skills, 99(1), 341-353. doi: 10.2466/pms.99.1.341-353

Ruijter, J., de Ruiter, M. B., Snel, J., \& Lorist, M. M. (2000). The influence of caffeine on spatial-selective attention: an event-related potential study. Clinical Neurophysiology, 111(12), 2223-2233. doi: 10.1016/S1388-2457(00)00462-4

Ruijter, J., Lorist, M. M., \& Snel, J. (1999). The influence of different doses of caffeine on visual task performance. Journal of Psychophysiology, 13(1), 37-48. doi: 10.1027//02698803.13.1.37 
Sablowski, N., \& Herrmann, H. D. (1986). Aspects of personality in patients with pituitaryadenomas. Acta Neurochirurgica, 83(1-2), 8-11. doi: 10.1007/BF01420501

Schmid-Leuz, B., Elsesser, K., Lohrmann, T., Jöhren, P., \& Sartory, G. (2007). Attention focusing versus distraction during exposure in dental phobia. Behaviour Research and Therapy, 45(11), 2691-2703. doi: 10.1016/j.brat.2007.07.004

Schneider, S. M., Ellis, M., Coombs, W. T., Shonkwiler, E. L., \& Folsom, L. C. (2003). Virtual Reality Intervention for Older Women with Breast Cancer. CyberPsychology \& Behavior, 6(3), 301-307. doi: 10.1089/109493103322011605

Schunck, T., Erb, G., Mathis, A., Jacob, N., Gilles, C., Namer, I. J., et al. (2008). Test-retest reliability of a functional MRI anticipatory anxiety paradigm in healthy volunteers. Journal of Magnetic Resonance Imaging, 27(3), 459-468. doi: 10.1002/jmri.21237

Schwerdtfeger, A., Schmukle, S. C., \& Egloff, B. (2006). Verbal-autonomic response dissociations as traits? Biological Psychology, 72(2), 213-221. doi: 10.1016/j.biopsycho.2005.11.003

Scott, J. P. R., McNaughton, L. R., \& Polman, R. C. J. (2006). Effects of sleep deprivation and exercise on cognitive, motor performance and mood. Physiology \& Behavior, 87(2), 396408. doi: 10.1016/j.physbeh.2005.11.009

Shioiri, T., Kuwabara, H., Abe, R., Lijima, A., Kojima-Maruyama, M., Kitamura, H., et al. (2006). Lack of a relationship between the pupillary light reflex response and state/trait anxiety in remitted patients with panic disorder. Journal of Affective Disorders, 95(1-3), 159164. doi: 10.1016/j.jad.2006.04.031

Sideridis, G. D. (2008). The regulation of affect, anxiety, and stressful arousal from adopting mastery-avoidance goal orientations. Stress and Health, 24(1), 55-69. doi: 10.1002/smi.1160

Simpson, E. E. A., McConville, C., Rae, G., O'Connor, J. M., Stewart-Knox, B. J., Coudray, C., et al. (2008). Salivary cortisol, stress and mood in healthy older adults: The Zenith study. Biological Psychology, 78(1), 1-9. doi: 10.1016/j.biopsycho.2007.12.001

Slaven, L., \& Lee, C. (1997). Mood and symptom reporting among middle-aged women: The relationship between menopausal status, hormone replacement therapy, and exercise participation. Health Psychology, 16(3), 203-208. doi: 10.1037/0278-6133.16.3.203

Starcke, K., Wolf, O. T., Markowitsch, H. J., \& Brand, M. (2008). Anticipatory stress influences decision making under explicit risk conditions. Behavioral Neuroscience, 122(6), 1352-1360. doi: 10.1037/a0013281

Startup, H. M., \& Davey, G. C. L. (2001). Mood as input and catatrophic worrying. Journal of Abnormal Psychology, 110(1), 83-96. doi: 10.1037/0021-843X.110.1.83

Steinberg, H., Nicholls, B. R., Sykes, E. A., LeBoutillier, N., Ramlakhan, N., Moss, T. P., et al. (1998). Weekly exercise consistently reinstates positive mood. European Psychologist, 3(4), 271-280. doi: 10.1027/1016-9040.3.4.271

Steptoe, A., \& Cox, S. (1988). Acute effects of aerobic exercise on mood. Health Psychology, 7(4), 329-340. doi: 10.1037/0278-6133.7.4.329 
Strentz, T., \& Auerbach, S. M. (1988). Adjustment to the stress of simulated captivity: Effects of emotion-focused versus problem-focused preparation on hostages differing in locus of control. Journal of Personality and Social Psychology, 55(4), 652-660. doi: 10.1037/00223514.55.4.652

Strigo, I. A., Bushnell, M. C., Boivin, M., \& Duncan, G. H. (2002). Psychophysical analysis of visceral and cutaneous pain in human subjects. Pain, 97(3), 235-246. doi: 10.1016/S03043959(02)00023-4

Sukegawa, A., Miyagi, E., Asai-Sato, M., Saji, H., Sugiura, K., Matsumura, T., et al. (2008). Anxiety and prevalence of psychiatric disorders among patients awaiting surgery for suspected ovarian cancer. Journal of Obstetrics and Gynaecology Research, 34(4), 543-551. doi: 10.1111/j.1447-0756.2008.00738.x

Swartzman, L. C., Edelberg, R., \& Kemmann, E. (1990). Impact of stress on objectively recorded menopausal hot flushes and on flush report bias. Health Psychology, 9(5), 529-545. doi: 10.1037/0278-6133.9.5.529

Swendsen, J. D. (1998). The helplessness-hopelessness theory and daily mood experience: An idiographic and cross-situational perspective. Journal of Personality and Social Psychology, 74(5), 1398-1408. doi: 10.1037/0022-3514.74.5.1398

Tang, J., \& Gibson, S. J. (2005). A psychophysical evaluation of the relationship between trait anxiety, pain perception, and induced state anxiety. Journal of Pain, 6(9), 612-619. doi: 10.1016/j.jpain.2005.03.009

Thompson, T., Altmann, R., \& Davidson, J. (2004). Shame-proneness and achievement behaviour. Personality and Individual Differences, 36(3), 613-627. doi: 10.1016/S01918869(03)00121-1

Tornek, A., Field, T., Hernandez-Reif, M., Diego, M., \& Jones, N. (2003). Music effects on EEG in intrusive and withdrawn mothers with depressive symptoms. PsychiatryInterpersonal and Biological Processes, 66(3), 234-243. doi: 10.1521/psyc.66.3.234.25157

Toskovic, N. N. (2001). Alterations in selected measures of mood with a single bout of dynamic Taekwondo exercise in college-age students. Perceptual and Motor Skills, $92(3 \mathrm{pt}$ 2), 1031-1038.

Tovilovic, S., Novovic, Z., Mihic, L., \& Jovanovic, V. (2009). The role of trait anxiety in induction of state anxiety. Psihologija, 42(4), 491-504. doi: 10.2298/psi0904491t

Tulen, J. H., Moleman, P., Blankestijn, P. J., Man in't Veld, A. J., van Steenis, H. G., \& Boomsma, F. (1993). Psychological, cardiovascular, and endocrine changes during 6 hours of continuous infusion of epinephrine or norepinephrine in healthy volunteers. Psychosomatic Medicine, 55(1), 61-69.

Urech, C., Fink, N. S., Hoesli, I., Wilhelm, F. H., Bitzer, J., \& Alder, J. (2010). Effects of relaxation on psychobiological wellbeing during pregnancy: A randomized controlled trial. Psychoneuroendocrinology, 35(9), 1348-1355. doi: 10.1016/j.psyneuen.2010.03.008

Vadalouca, A., Moka, E., Chatzidimitriou, A., Siafaka, I., Sikioti, P., \& Argyra, E. (2009). A randomized, double-blind, placebo-controlled study of preemptively administered intravenous parecoxib: effect on anxiety levels and procedural pain during epidural catheter 
placement for surgical operations or for chronic pain therapy. Pain Practice, 9(3), 181-194. doi: 10.1111/j.1533-2500.2009.00271.x

van der Bij, A. K., de Weerd, S., Cikot, R. J. L. M., Steegers, E. A. P., \& Braspenning, J. C. C. (2003). Validation of the dutch short form of the state scale of the Spielberger State-Trait Anxiety Inventory: considerations for usage in screening outcomes. Community Genet, 6(2), 84-87. doi: 10.1159/000073003

Verburg, K., Pols, H., de Leeuw, M., \& Griez, E. (1998). Reliability of the 35\% carbon dioxide panic provocation challenge. Psychiatry Research, 78(3), 207-214. doi: 10.1016/S0165-1781(98)00009-2

Villani, D., Riva, F., \& Riva, G. (2007). New technologies for relaxation: The role of presence. International Journal of Stress Management, 14(3), 260-274. doi: 10.1037/10725245.14.3.260

Vujanovic, A. A., \& Zvolensky, M. J. (2009). Anxiety sensitivity, acute nicotine withdrawal symptoms, and anxious and fearful responding to bodily sensations: A laboratory test. Experimental and Clinical Psychopharmacology, 17(3), 181-190. doi: 10.1037/a0016266

Weisberg, R. B., Brown, T. A., Wincze, J. P., \& Barlow, D. H. (2001). Causal attributions and male sexual arousal: The impact of attributions for a bogus erectile difficulty on sexual arousal, cognitions, and affect. Journal of Abnormal Psychology, 110(2), 324-334. doi: $10.1037 / 0021-843 X .110 .2 .324$

Werner, N. S., Duschek, S., Mattern, M., \& Schandry, R. (2009). Interoceptive sensitivity modulates anxiety during public speaking. Journal of Psychophysiology, 23(2), 85-94. doi: 10.1027/0269-8803.23.2.85

Wilson, E. J., MacLeod, C., \& Mathews, A. (2006). The Causal Role of Interpretive Bias in Anxiety Reactivity. Journal of Abnormal Psychology, 115(1), 103-111. doi: 10.1037/0021843X.115.1.103

Wolanskyj, A. P., Schroeder, G., Wilson, P. R., Habermann, T. M., Inwards, D. J., \& Witzig, T. E. (2000). A randomized, placebo-controlled study of outpatient premedication for bone marrow biopsy in adults with lymphoma. Clin Lymphoma, 1(2), 154-157. doi: 10.3816/CLM.2000.n.014

Yiend, J., Mathews, A., Weston, B., Cusack, R., Mackintosh, B., \& Dunn, B. D. (2008). An investigation of the implicit control of the processing of negative pictures. Emotion, $8(6)$, 828-837. doi: 10.1037/a0014146

Youngstedt, S. D., \& Kripke, D. F. (2007). Does bright light have an anxiolytic effect? an open trial. Bmc Psychiatry, 7, 5. doi: 10.1186/1471-244X-7-62 